\title{
Servicios sociales e inclusión social: análisis y perspectivas en el País Vasco
}

\section{Fernando Fantova}

Consultor social

$<$ fernando@fantova.net>
Gizarteratzearen politika orokorraren inguruan euskal gizarte-zerbitzuen sistemak egin ditzaken ekarpenen inguruko analisi kritiko bat burutzen da artikulu honetan (gaitasun, egokitasun, kongruentzia eta partaidetzaren inguruan), betiere Gizarte Zerbitzuetako euskal Legeak eta arautegiaren garapenak eskuartze sozialerako eta antolaketa operatiboan dituen osagai batzuen inguruan. Bertan aztertzen dira ondorengo alderdi hauek: gizarte-zerbitzuen zergatia eta espero daitezkeen emaitzak; pertsonen egoeren inguruko diagnostiko, balioztapen eta ebaluazioa; eskuartze sozialeko prozeduren printzipioak, osagaiak eta dinamika; gizarte-zerbitzuetako ibilbide, segmentazio, espezializazio eta integrazio bertikala; gizartezerbitzuetako eta bestelako jarduera-eremuen sektoreen arteko integrazioa; eta eskuartze sozialeko prozeduretako eragileen sarea.

\section{GAKO-HITZAK:}

Gizarte-zerbitzuak, gizarteratzea, eskuartze soziala, arautegia, Euskadi.
Como aportación a un examen propositivo de la contribución del sistema vasco de servicios sociales a la política general de inclusión, se efectúa un análisis crítico (en términos de suficiencia, adecuación, congruencia o pertinencia) de algunos elementos del modelo de intervención social y de organización operativa de los servicios sociales propuesto (de forma más o menos explícita y completa) por la Ley vasca de Servicios Sociales y su normativa de desarrollo, abordándose los siguientes aspectos: el objeto de los servicios sociales y sus resultados esperados; el diagnóstico, valoración o evaluación acerca de la situación de las personas; los principios, los ingredientes y la dinámica de los procesos de intervención social; los itinerarios, la segmentación, la especialización y la integración vertical en los servicios sociales; la integración intersectorial entre los servicios sociales y otros ámbitos de actividad; y la red de agentes en los procesos de intervención social.

\section{Palabras Clave:}

Servicios sociales, inclusión social, intervención social, normativa, País Vasco. 


\section{Presentación}

Este artículo pretende ser una aportación a algunas reflexiones y debates en curso en la comunidad de práctica y aprendizaje de los servicios sociales en el País Vasco; reflexiones y debates que tienen que ver con la contribución del sistema vasco de servicios sociales a la política general de inclusión social o, que las cuestiones o asuntos relacionados con la inclusión social tienen y pueden tener en el marco de nuestra política sectorial de servicios sociales. Se incluye dentro de un número monográfico de Zerbitzuan preparado con motivo de la elaboración de un nuevo Plan Vasco de Inclusión.

Cuando nos acercamos al décimo aniversario de la aprobación de nuestra Ley de Servicios Sociales (12/2008), que fue incubándose en algunos de sus aspectos técnicos desde años antes (Fantova et al., 2005), hemos de reconocer que su desarrollo y aplicación está muy lejos de las previsiones establecidas en el propio texto, siendo quien escribe entre otras razones, por haber sido viceconsejero de Asuntos Sociales del Gobierno Vasco en la legislatura inmediatamente posterior a la de la aprobación de la Ley.

Sin poder entrar a fondo ahora en el conjunto de factores explicativos de dicha situación, algunos de los cuales han sido analizados en una reciente tesis doctoral (Arrieta, 2015), cabe pensar que uno de ellos pueda ser el de la (relativa) inadecuación, incoherencia, impertinencia o insuficiencia, en algunos aspectos, del modelo de intervención social y de organización operativa de los servicios sociales propuesto (de forma más explícita o implícita, de desarrollo, lo cual dificulta su implementación, gestión y gobernanza.

En este artículo, por ello, se busca identificar y examinar algunas de esas posibles deficiencias 'técnicas' presentes o subyacentes en nuestro marco despliegue del sistema público de servicios sociales que menos se resienta de ellas y, eventualmente, de alumbrar en alguna medida vías de desarrollo, mejora, innovación y transformación de nuestros servicios sociales para una mejor respuesta futura a la ciudadanía ${ }^{1}$. dicho de otro modo, con el encaje y tratamiento este artículo, en todo caso, corresponsable de ello, completa o fragmentaria) por la Ley y su normativa jurídico, con el fin, de entrada, de poder plantear el

\section{Cuestiones a tratar, dimensiones a analizar y método de examen}

En el análisis sobre la contribución de los servicios sociales a la inclusión social, se irá haciendo un repaso sobre los siguientes seis aspectos:

- El objeto de los servicios sociales y sus resultados esperados.

- El diagnóstico, valoración o evaluación acerca de la situación de las personas.

- Los principios, los ingredientes y la dinámica de los procesos de intervención social.

- Los itinerarios, la segmentación, la especialización y la integración vertical en los servicios sociales.

- La integración intersectorial entre los servicios sociales y otros ámbitos de actividad.

- La red de agentes en los procesos de intervención social.

Sobre cada una de estas cuestiones, podremos hacer observaciones en términos de:

- Suficiencia, es decir, sobre si la normativa o, en su caso, la comunidad de práctica y conocimiento de los servicios sociales vascos dispone de conocimiento o instrumentos para abordar o resolver tal cuestión.

- Adecuación, es decir, sobre si la normativa o, en su caso, el conocimiento o instrumental disponible está basado en la evidencia o se ajusta a los consensos establecidos en las comunidades científicas y técnicas de referencia.

- Coherencia, es decir, sobre si el modelo de intervención social y de organización operativa de los servicios sociales que estamos analizando es congruente internamente, o si contiene contradicciones.

- Pertinencia, es decir, si, en definitiva, este modelo responde a las necesidades de las personas y a los retos del contexto actual.

Para ello, partiendo de libros y artículos escritos anteriormente (especialmente, Fantova, 2008, 2014 y 2016), el autor se apoyará en el conocimiento obtenido a través de la participación directa en procesos de diseño, implementación y evaluación de nuestros servicios sociales y a través del acceso a documentación de referencia, buscando alcanzar conclusiones plausibles y propuestas aplicables, que, en todo caso, se someten a la consideración, crítica, mejora o sustitución por parte de quienes tengan acceso a estas páginas.

\section{Conceptos de referencia}

${ }^{1}$ La elaboración de este artículo se ha visto impulsada y facilitada por un encargo de asistencia técnica de la Dirección de Inclusión de la Diputación Foral de Bizkaia, en la medida en que algunos procesos de búsqueda y procesamiento de información han servido tanto para el trabajo de consultoría como para la elaboración del artículo.
Según el esquema de conceptos de referencia para operar que hemos tenido ocasión de construir, presentar y contrastar en anteriores trabajos, nos 
aproximamos a los servicios sociales en tanto que sector de actividad regulado por una política pública social (de carácter, por tanto, sectorial) y, en tanto que tal, potencialmente universal, es decir, capaz de dar respuesta a una necesidad o conjunto de necesidades que todas las personas poseamos. Dentro del ámbito sectorial de los servicios sociales, encontramos el sistema público de servicios sociales, entendido como la parte del sector que es de responsabilidad pública.

Denominamos intervención social al conjunto de actividades o procesos operativos que caracterizan y diferencian a los servicios sociales y que desembocan finalmente (de forma más o menos directa) en las personas destinatarias de los servicios sociales, permitiéndoles dar satisfacción a determinadas necesidades y obtener determinados resultados valiosos para ellas. El tipo o conjunto de necesidades de las que se ocupan los servicios sociales (o, dicho de otro modo, el conjunto o tipo de resultados que desencadena la intervención social) constituyen el objeto de los servicios sociales (y de la intervención social). Los procesos de intervención social son centrales y fundamentales en los servicios sociales, aunque también se producen (de forma secundaria y complementaria) en otras ramas de la política social y, en general, en otros ámbitos sectoriales.

Los procesos de intervención social, como tantos otros procesos en diversos ámbitos de la actividad económica, la política pública y la vida social, tienen una dinámica cíclica en la que se encabalgan tres tipos de momentos o subprocesos: de evaluación (que incluyen actividades de diagnóstico o valoración), de planificación (que incluyen actividades de prescripción y de ejercicio de la autonomía moral, consentimiento informado y toma de decisiones de la persona destinataria) y de ejecución o implementación.

Los procesos de intervención social contienen ingredientes (actividades, apoyos, prestaciones) propios o característicos de los servicios sociales, y también otros típicos de otros ámbitos sectoriales (como alojamiento, trabajo doméstico, cuidados de enfermería o seguridad) o presentes en todos los ámbitos sectoriales (como determinadas actividades de gestión). El conocimiento y métodos utilizados en los procesos de intervención social es aportado, hoy y aquí, fundamentalmente (no únicamente) por tres áreas de conocimiento (disciplinas y profesiones): el trabajo social, la educación (y pedagogía) social y la psicología de la intervención social.

La regulación de los itinerarios de la población en el disfrute de los servicios sociales obliga a tomar opciones organizativas en el terreno de la configuración de servicios estables (conjuntos de actividades disponibles en forma recurrente), y rutas de acceso y egreso para cada uno de esos servicios, produciéndose una mayor o menor (y un tipo u otro de) especialización o integración en y entre dichos servicios. A esa integración entre eslabones de las cadenas de valor que se produce en el interior de cada sector de actividad (en este caso, dentro del ámbito de los servicios sociales), la llamamos integración vertical, a diferencia de la integración horizontal o intersectorial, que incorpora actividades o servicios propios de diferentes ámbitos sectoriales (OCDE, 2015: 17). Denominamos organización operativa a estas decisiones organizativas más próximas a los procesos de intervención social, para diferenciarlas de otras opciones organizativas de carácter más 'macro', sobre las que no se focaliza este artículo.

En la medida en que suceden los procesos de intervención social y se va organizando la prestación de servicios sociales a las personas (integrándose vertical y horizontalmente), diferentes tipos de agentes (públicos, privados, solidarios y comunitarios) van participando en dichos procesos con diferentes funciones (como garantía de derechos, ejecución de la intervención, representación de intereses, construcción de conocimiento u otras).

Utilizando estos conceptos y accediendo a la actividad y producción normativa y técnica de los servicios sociales en la Comunidad Autónoma del País Vasco, se va a intentar, a continuación, abordar las seis cuestiones antes enunciadas para proponer una valoración sobre ellas (teniendo en cuenta las cuatro dimensiones mencionadas).

\section{Objeto de los servicios sociales y sus resultados esperados}

Como recuerda Manuel Aguilar (2014: 19), “lo que llamamos servicios sociales son un híbrido, un campo en proceso de transformación desde el antiguo nivel de la beneficencia o la asistencia social hacia un nuevo sector o pilar del Estado de bienestar" Por ello, "es necesario establecer y delimitar con claridad el campo de acción de los servicios sociales" y, "en principio, parece lógico y coherente con la arquitectura del Estado social en España configurar los servicios sociales como un pilar definido por la parte de las necesidades humanas de las que se ocupa" (ibídem: 29).

Al respecto, parece fuera de duda que la Ley vasca de Servicios Sociales de 2008 representa un avance en cuanto a la acotación del objeto o perímetro sectorial (de necesidades de las personas y de resultados esperados) que corresponde a los servicios sociales. Así, mientras que la ley anterior, de 1996, hablaba en su artículo 1 de "prevenir y eliminar las causas de marginación social y de desigualdad; promover la integración social de las personas y colectivos, y favorecer el pleno y libre desarrollo de las personas y los colectivos, adecuándose para ello al modelo actual de sociedad", la actualmente vigente señala en su exposición de motivos que la finalidad de los servicios sociales es "favorecer la integración social y la autonomía de todas las personas, 
familias y grupos, desarrollando una función promotora, preventiva, protectora y asistencial, a través de prestaciones y servicios de naturaleza fundamentalmente personal y relacional”.

En ese y otros pasajes de la Ley, se juega con el par autonomía/integración, que ya aparecía en el dosier previo a la Ley (Fantova et al., 2005: 11), en el que se oponía el concepto de autonomía al de dependencia (funcional, se entiende) y en el que el sustantivo "integración" se acompañaba con el adjetivo “comunitaria”. En el artículo 6.3. de la ley de 2008, se afirma que "el bienestar social, la inclusión social y la cohesión social no constituyen finalidades exclusivas del sistema vasco de servicios sociales, sino compartidas con otros sistemas y políticas públicas de protección social", lo que resulta coherente con el consenso de la comunidad científica en relación con el concepto de exclusión (Laparra et al., 2007).

Por otra parte, hay que recordar que pocos días después de entrar en vigor la Ley de Servicios Sociales, lo hacía la que regula el sistema de garantía de ingresos para la subsistencia (Ley 18/2008), entendido como un sistema distinto del sistema público de servicios sociales. Tal distinción quedó reforzada, si cabe, en la reforma legislativa de 2011, en la que se trasladó desde los servicios sociales a los servicios de empleo la gestión de las prestaciones económicas de derecho de ese sistema de garantía de ingresos. Gestión de prestaciones económicas de derecho que, según la exposición de motivos de la ley de 2011, "dificultaba el ejercicio adecuado de sus funciones básicas de gestión de caso y de intervención social" en los servicios sociales (de base, específicamente).

Se ha de reconocer, sin embargo, que, en diferentes pasajes de la Ley vasca de Servicios Sociales de 2008, se ensancha el perímetro, como ocurre, por ejemplo, en los momentos en los que se identifica la exclusión (social, se entiende, sin mayor acotación) como asunto que corresponde abordar a los servicios sociales (como en el artículo 6.1.c.), lo cual, a nuestro juicio, resulta contradictorio con la afirmación del artículo 6.3. que acabamos de evocar. El propio catálogo de servicios sociales (artículo 22) habla del "servicio de valoración y diagnóstico de la dependencia, la discapacidad, la exclusión y la desprotección" como servicio de atención secundaria que permitirá establecer la existencia de dichas contingencias o situaciones (de atender a las cuales se ocupará el resto de servicios sociales de atención secundaria).

Posteriormente, por ejemplo, en el Decreto 353/2013, de 28 de mayo, de Ficha Social del Sistema Vasco de Servicios Sociales y del Instrumento de Diagnóstico Social del Sistema Vasco de Servicios Sociales, se acentúa ese rebasamiento del perímetro sectorial indicado. Así, si bien la Ley habla de las "necesidades sociales susceptibles de ser atendidas en el ámbito de los servicios sociales” (por ejemplo, en el artículo 6), este decreto entiende que los servicios sociales se ocupan de (se entiende que todas) las "necesidades sociales".

Además, el artículo 3 del Decreto 353/2013 identifica los siguientes “ámbitos generales de actuación del sistema”, al decir que una persona puede ser atendida por los servicios sociales por los siguientes motivos:

- Para recabar información sobre servicios y prestaciones del sistema de servicios sociales.

- Para recabar información sobre servicios y prestaciones de otros sistemas de protección social.

- Sobre temas relacionados con la atención a la dependencia.

- Sobre temas relacionados con la desprotección.

- Sobre temas relacionados con la exclusión social.

- Sobre temas relacionados con los medios de subsistencia.

- Sobre temas relacionados con la participación social.

El instrumento de diagnóstico social que constituye el anexo II del mencionado decreto consta de 172 indicadores, ordenados por 17 dimensiones:

1. Situación económica.

2. Situación ocupacional-laboral.

3. Situación residencial [se refiere a cuestiones como empadronamiento o autorización de residencia].

4. Situación de alojamiento y de vivienda.

5. Vínculos afectivos y recepción de apoyo social.

6. Situación relacional convivencial, personal, familiar.

7. Organización de la vida cotidiana.

8. Relaciones convivenciales en otros contextos.

9. Competencias-habilidades sociales.

10. Educación: formación-información-capacitación.

11. Dinamismos vitales [como, por ejemplo, “motivación al cambio"].

12. Usos de los sistemas de protección [tales como "redes primarias", "redes secundarias" o

"recursos sociales"].

13. Situación de la salud.

14. Situación de discapacidad e incapacidad laboral.

15. Aceptación social y convivencia cotidiana comunitaria.

16. Adaptación al medio social y normativo.

17. Disponibilidad de relaciones sociales y ejercicio de la participación social.

Sin entrar ahora en otras consideraciones, puede afirmarse que este listado de dimensiones, tal como se presenta, parece indicar que todas ellas fueran igualmente relevantes para ser diagnosticadas y abordadas por parte de los servicios sociales. 
Cabría aducir que algunas de dichas dimensiones se mencionan en tanto que directamente abordables por parte de los servicios sociales, y otras, que competen a otros ámbitos sectoriales, ofrecerían información contextual útil, pero tal distinción no aparece en el Decreto, y ni siquiera del orden, detalle o estilo de tratamiento de las diversas dimensiones se deduce que unas sean consideradas como objeto de los servicios sociales y otras no.

Como propuesta (una, obviamente discutible) frente al riesgo de ampliar excesivamente o difuminar inadecuadamente el perímetro sectorial de las necesidades o situaciones de las que se ocuparían los servicios sociales, cabe presentar la que, en un intento de recepción, sistematización y desarrollo de diversas aportaciones, propone identificar la interacción (Fantova, 2007, 2008) como objeto de la intervención social y los servicios sociales.

Para dibujar el perímetro de las situaciones que, según esta propuesta, corresponde a los servicios sociales, podemos seguir la pista de personas de carne y hueso en sus itinerarios. Pensemos en una persona que tiene un accidente y resulta gravemente herida. No cabe duda de que en ese momento su situación debe ser abordada cuanto antes por parte de los servicios sanitarios. Imaginemos que es tratada en un hospital, donde, además de las prestaciones típicamente sanitarias (como intervención quirúrgica, terapia farmacológica o cuidados de enfermería), disfrutará de otras que no lo son (como la alimentación, el alojamiento o el servicio doméstico). Además, empezará a cobrar una prestación económica para su subsistencia. Una vez dada de alta hospitalaria, esta persona seguirá recibiendo apoyos sanitarios (como, por ejemplo, actividades ambulatorias o domiciliarias de rehabilitación).

Pensemos en el caso de que esta persona presente, en ese momento, limitaciones funcionales, es decir, un menoscabo de su autonomía funcional. Ello puede afectarle, por ejemplo, en el ámbito laboral (quizá no pueda seguir realizando el mismo trabajo que antes), en el del alojamiento (quizá no pueda acceder como antes a su vivienda) o en el ámbito de su vida diaria y relaciones primarias (quizá se vea afectada la relación de convivencia que tenía con otras personas). Parece claro, por tanto, que la reparación de determinadas estructuras orgánicas y la recuperación de cierta autonomía funcional compete al sector sanitario, pero, a partir de un determinado punto, la persona se desenvuelve en diferentes entornos (laboral, residencial y relacional, según los tres ejemplos), de suerte que la integración o inclusión (laboral, residencial y relacional) puede verse como la otra cara de la autonomía funcional en cada uno de ellos (y equilibrarse e interactuar dinámicamente con ella).

Siguiendo con los tres ámbitos mencionados, los servicios de empleo serían los encargados de apoyar a la persona en su proceso de reincorporación al mercado laboral, eventualmente pasando por el sistema educativo para adquirir nuevas competencias profesionales, mientras que los servicios de vivienda deberían ayudarle a adaptar su domicilio o, en su caso, a acceder a uno nuevo. Los servicios sociales, según la propuesta que estamos presentando, le apoyarían en la potenciación de su autonomía funcional para la vida diaria (actual y futura) en acoplamiento (a, con o) en el entorno relacional familiar y comunitario.

Lógicamente, a esa parcela de necesidades y situaciones cuyo perímetro estamos dibujando se llega por otros itinerarios. Como el de la niña con buen estado de salud seguida por su pediatra y cuya tutora en la escuela tiene indicios de que no cuenta con un cuidado y ambiente familiar positivo. 0 el de la pareja que comienza a convivir y a organizar su vida en común. 0 el del hombre jubilado que acaba de enviudar y comienza a vivir solo. 0 el del joven que hace vida en la calle del barrio en la que se detectan conflictos de convivencia entre personas de comunidades culturales diferentes. Y así sucesivamente.

La intervención social sería, entonces, la actividad que tiene como finalidad prevenir, corregir o paliar desajustes en lo relativo a la interacción de las personas, con sus dos caras o dimensiones: autonomía funcional e integración relacional. Una autonomía funcional para la vida diaria, que comprendería desde el autocuidado o cuidado en la ejecución de las actividades básicas de la vida diaria hasta la utilización de las funciones cognitivas y emocionales para la toma de decisiones sobre la propia vida y su futuro (autodeterminación, autoorganización o autogobierno), pasando por habilidades sociales para las relaciones cotidianas. $Y$ una integración relacional, que se referiría tanto a los vínculos familiares como a otras redes comunitarias presenciales o virtuales, actuales o posibles (todas ellas, relaciones primarias), fuente primordial de apoyo social. La intervención social, por tanto, estaría llamada a obtener resultados, entendidos como cambios factibles, evaluables y evidentes en la interacción de las personas, en ese ajuste dinámico entre la autonomía funcional para la vida cotidiana y la integración relacional en redes primarias.

Se entiende que esta propuesta permite avanzar en el asentamiento de la intervención social y los servicios sociales como conceptual y tendencialmente universales (no residuales) y, por lo tanto, sectoriales (no transversales). Y que les ofrece un objeto de interés para (todas) las personas y susceptible de ser estudiado y abordado desde diversas áreas científicas y técnicas de conocimiento, tanto como lo puedan ser los objetos de otras ramas sectoriales de la política social (salud, empleo u otros). Y que, desde un punto de vista estratégico, puede ofrecer a los servicios sociales oportunidades de existencia, continuidad, legitimidad y sostenibilidad en la medida del valor de sus resultados para las personas, para la población, 
diferenciados de (y sinérgicos con) los que es capaz de desencadenar la intervención sanitaria, educativa, laboral u otras.

Cabe decir, por cierto, que, en el proceso de elaboración del instrumento de valoración de la exclusión, que finalmente dio lugar al Decreto $385 / 2013$, de 16 de julio, por el que se aprueba el Instrumento de Valoración de la Exclusión Social, se adopta este concepto de interacción (Fantova, 2008) como referencia a la hora de delimitar qué situaciones de exclusión corresponde abordar a los servicios sociales (Ormaetxea, 2011: 27-30).

Sea como fuere, en este primer punto se ha querido poner de manifiesto la contradicción interna y la inadecuación conceptual que supone considerar la exclusión social y la inclusión social como la situación (o como una situación) de la que se ocupan (especialmente) los servicios sociales. Al contrario, se entiende que la intervención social puede desencadenar resultados valiosos en lo tocante a la exclusión relacional (de las redes familiares y comunitarias), correspondiendo a otros ámbitos sectoriales otras dimensiones de la inclusión social, como pueden ser la laboral, la residencial o la económica. En palabras de Manuel Aguilar et al. (2012: 21), "la tarea propia y central de los servicios sociales en las políticas de inclusión e incorporación es el trabajo de 'apoyo social a la incorporación'. Este trabajo social puede definirse como un proceso de 'acompañamiento del desarrollo personal en el contexto de la comunidad”".

\section{Diagnóstico, valoración o evaluación acerca de la situación de las personas}

Como recuerdan María Paz García-Longoria y Rosa María Esteban (2016: 14):

En 1949 se creó el Social Work Research Group, que en 1955 entró a formar parte de la National Association of Social Work. Este grupo enunció ocho tipos de contenidos de las investigaciones sobre trabajo social [...]:

- Determinación de la necesidad de servicios sociales.

- Evaluación de la adecuación y efectividad de los servicios.

- Investigación del contenido de los procesos.

- Investigación de la pericia requerida para las variadas operaciones.

- Validación de la teoría y los conceptos.

- Desarrollo de la metodología e instrumentos.

- Investigación del desarrollo y vigencia de los programas, servicios y conceptos.

- Traslación y prueba de la teoría y conocimientos tomados de otros campos.

En ese marco, cabe entender que, en el trabajo social o en las otras áreas de conocimiento involucradas en la intervención social, la operación de diagnosticar, valorar o evaluar las necesidades o situaciones a las que se quiere dar respuesta puede (y debe) hacerse antes de decidir (planificar, prescribir, proponer) poner en marcha la intervención y, lógicamente, también después, tantas veces como sea oportuno. Como en cualquier otro ámbito sectorial, el diagnóstico, valoración y evaluación pertinentes y útiles serán los que se circunscriban adecuadamente al perímetro sectorial de necesidades, apoyos, situaciones o contingencias correspondientes a la actividad sectorial característica o propia. No tiene sentido pretender diagnosticar, valorar o evaluar necesidades o situaciones de la persona para cuyo abordaje no tenemos el encargo y el instrumental correspondientes.

Obviamente, fortalecer la capacidad de diagnóstico, valoración y evaluación resulta crítico y depende en buena medida de la capacidad de las disciplinas científicas y técnicas involucradas en la intervención social de aportar o desarrollar herramientas e instrumentos capaces de identificar y medir necesidades y situaciones a partir de conceptos y constructos rigurosos y contrastados, bien enfocados y delimitados. Herramientas e instrumentos fiables y válidos, que aporten cada vez mayor valor añadido en el proceso que comienza con la recogida de información y desemboca en el juicio profesional que antecede a la prescripción facultativa.

Ciertamente, no está de más decir que no hay (no debe haber) un juego de suma cero entre la capacidad diagnóstica profesional y el ejercicio de la autonomía moral, el consentimiento informado y el empoderamiento por parte de la persona destinataria, incluso en términos de "codiagnóstico" (Cardona et al., 2017: 151). Yo, como usuaria de los servicios sociales no tengo más control de mi situación cuanto menos capaz sea la profesional de evaluarla, sino, en principio, todo lo contrario. Pero eso depende, efectivamente de cómo se diseñe, instrumente, ejecute y supervise la labor de diagnóstico, valoración y evaluación.

Al respecto, la normativa vasca de servicios sociales hace referencia al diagnóstico que los servicios sociales de atención primaria realizarán, en principio, con el instrumento recogido en el ya mencionado Decreto 353/2013. En el preámbulo de este decreto, se afirma que "al margen de estas herramientas técnicas generales, los servicios especializados dispondrán de otras herramientas de diagnóstico específicas e independientes para valorar un tipo de problema determinado. Algunos de dichos instrumentos comunes ya existen -instrumento para la valoración de la gravedad de las situaciones de riesgo en los servicios sociales municipales y territoriales de atención y protección a la infancia y adolescencia en el País Vasco (Balora) o los baremos de valoración de la dependencia (BVD y EVE)-, mientras que está pendiente el desarrollo de otros instrumentos posibles, tales como los instrumentos de valoración de la exclusión social o de la desprotección de personas adultas". Como sabemos, 
con posterioridad a este decreto, se publicó el Decreto $385 / 2013$, de 16 de julio, por el que se aprueba el Instrumento de Valoración de la Exclusión Social.

En lo tocante al instrumento de diagnóstico general, a pesar de ser el fruto de una trayectoria esforzada y prolongada de trabajos en los que han colaborado muchas profesionales experimentadas y competentes de los servicios sociales, su utilización es “escasa” (Orbegozo, 2016) y, en nuestra búsqueda bibliográfica, no hemos encontrado ningún artículo o documento similar que refleje operaciones de utilización del instrumento, explotación de datos, juicios sobre su validez o propuestas de mejora, aunque, al menos, Izaskun Ormaetxea ha realizado, antes y después de la aprobación del Decreto, trabajos de consultoría que pueden llegar a ofrecer ese tipo de aportes, algunos de cuyos avances y alcances ha compartido en diversas jornadas profesionales. Dado el modelo de referencia que adopta nuestra normativa, la capacidad de diagnóstico, valoración y evaluación de necesidades y situaciones por parte del nivel de atención primaria es fundamental, en la medida en que resulta imprescindible para la atención preventiva, proactiva y personalizada que se propugna.

Como preguntas o consideraciones que cabría hacerse a la hora de evaluar la idoneidad de este instrumento de diagnóstico y que podrían ser, eventualmente, de ayuda en su futuro proceso de mejora o, en general, tenidas en cuenta en las labores de diagnóstico, valoración o evaluación de las necesidades y situaciones de las personas en los servicios sociales (y específicamente en la atención primaria), se podría plantear en qué medida es conveniente o apropiado:

- Diferenciar, en la información que se registra, la que se refiere a necesidades o situaciones a abordar por parte de los servicios sociales de la que se refiere a necesidades o situaciones correspondientes a otros ámbitos sectoriales.

- Reducir, quizá, la cantidad de información sobre cuestiones que corresponden a otros ámbitos sectoriales (y más bien optar, en los casos en que sea necesario, por la interoperabilidad entre sistemas de información de diferentes ámbitos sectoriales).

- Identificar, en la información que se recaba y registra (con el fin de poder llegar al diagnóstico), sus fuentes (la persona usuaria, la profesional que diagnostica, otras profesionales o sistemas, u otras).

- Explicitar (en el propio instrumento general o con otros) el procedimiento mediante el cual se llega a un determinado diagnóstico, y diferenciar entre la información que se recaba para llegar a él y el diagnóstico o diagnósticos propiamente dichos.

Por otra parte, en la Ley se señala que la diferencia entre la atención secundaria y la atención primaria está en la intensidad del apoyo (artículo 19.4.b.), que cabe interpretar como cantidad de prestación profesional por persona destinataria y periodo de tiempo (por ejemplo, una hora semanal de atención individual por parte de profesional de la educación social). Sin embargo, si bien en la exposición de motivos considera que tanto la atención primaria como la secundaria pueden considerarse especializadas, denomina diagnóstico y valoración de carácter especializado al que da paso, en su caso, a la atención secundaria. Se entiende que si, atendiendo a las situaciones o contingencias de las que se habla en diferentes lugares de la normativa (discapacidad, dependencia, desprotección y exclusión), únicamente hay una situación de fragilidad, vulnerabilidad o riesgo de incurrir en ellas $-y$, por tanto, la atención que requerimos en relación con ellas es menos intensa o especializada-, no seremos objeto, en principio, de diagnóstico especializado para una eventual derivación a la atención secundaria.

En cualquier caso, el sistema dirige la mirada del personal de atención primaria a ubicar a la persona en (o hacia) una de esas cuatro (o, a veces, tres) categorías. Por ejemplo, el decreto de Cartera, en su artículo 20.5., dirá que:
En la elaboración del Plan de Atención Personalizada, el o la profesional referente promoverá la atención temprana de las situaciones que hayan podido detectarse, tanto de exclusión, desprotección, dependencia y/o discapacidad, como de riesgo de exclusión, desprotección y/o dependencia, teniendo presente la posible interacción entre las cuatro contingencias, realizando un seguimiento de su evolución y, cuando proceda, realizando o solicitando, una primera baremación o su actualización.

Sin embargo, cabe cuestionar en qué sentido y en qué medida estamos hablando realmente de contingencias o situaciones diferenciadas en lo que corresponde a su abordaje por parte de los servicios sociales. Así, en la presentación proyectada por Izaskun Ormaetxea en la IV Jornada Gizartegune de la Diputación Foral de Bizkaia (2015: 15) se recoge la experiencia de valorar la situación de 90 personas (en situación de exclusión, según el correspondiente instrumento de valoración) atendidas por los servicios sociales de atención primaria del Ayuntamiento de Bilbao, también, en relación con las contingencias de dependencia y desprotección. De esas personas, 63 (un $70 \%$ ) presentan simultáneamente situación de dependencia, desprotección y exclusión; 10 (un $11,1 \%$ ) presentan dependencia y exclusión; 11 (un 12,2 \%), desprotección y exclusión; y 6 (un 6,7\%), únicamente exclusión.

En esta línea, recordarán Auxiliadora González y Germán Jaraíz (2014: 148-149) que:

Con los procesos de desprotección, dependencia y exclusión coexisten una serie de pérdidas 
(comunes de todos ellos); hablamos de: redes, vínculos personales y colectivos, confianzas, seguridades, convicciones en torno al presente y al futuro. Todas esas cuestiones se construyen, transforman o destruyen en torno a eso que hemos llamado 'la comunidad'.

Desde una perspectiva conceptual, las personas con limitaciones funcionales (y, específicamente, discapacidad y, en su caso, dependencia), como hemos dicho, interactúan en diversos entornos, de suerte que, evidentemente, tanto la discapacidad como la dependencia son asuntos transversales a diversos ámbitos sectoriales y, en cada uno de ellos, habrán de tomarse en cuenta tanto las limitaciones funcionales como la influencia del entorno en cuestión (y su inclusión o integración relacional, laboral, residencial u otras), tal como señalan los modelos de referencia para la comprensión y el abordaje de las discapacidades (OMS, 2001; Schalock et al., 2008). Por otra parte, en el caso de una criatura 0 , por poner otro ejemplo, de una persona adulta con limitaciones significativas en su capacidad de autogobierno (limitaciones funcionales, en ambos casos, en comparación con una persona adulta capaz de autogobernarse), no se percibe qué diferencia hay entre la situación de desprotección (por parte de su familia) y la situación de exclusión relacional (en lo relativo a sus relaciones primarias), que sería, conceptualmente, un aspecto o dimensión de la exclusión social.

Lo que se quiere decir es que lo que interesa a los servicios sociales no puede ser la global o transversal situación de dependencia (o discapacidad) funcional o de exclusión social de la persona, sino, al menos desde la definición de objeto y perímetro presentadas, la interacción entre las capacidades (o limitaciones) funcionales para la vida diaria y los soportes relacionales (o su ausencia) por parte de los entornos familiares y comunitarios en los que tiene lugar esa vida diaria. En los servicios sociales (como en los sanitarios, educativos u otros), identificar a alguien en función de su mayor o menor dependencia funcional o exclusión social es, por un lado, decir demasiado poco (porque falta información relevante) y, por otro, decir demasiado (porque sobra información no relevante).

Si aceptamos esa visión, el cometido tradicional de los servicios sociales que más fácilmente encaja en el perímetro propuesto es el de la desprotección de la infancia y la adolescencia. Ciertamente, el instrumento Balora, para la valoración de la gravedad de las situaciones de riesgo y desamparo en lo que tiene que ver con la protección y desprotección de la infancia y la adolescencia es, sin duda, un instrumento mucho más desarrollado, utilizado, contrastado y validado que el instrumento de diagnóstico general del que hemos hablado, y asume que toda persona menor de edad presenta, en principio y por definición, una limitación (y, por tanto, una necesidad de apoyo) en cuanto a su autonomía funcional: desde una dependencia funcional grandísima al nacer hasta la limitación (presunta) para tomar determinadas decisiones en relación con su vida cuando es adolescente y hasta entrar en la edad adulta. Por eso, el instrumento establece diferencias, por ejemplo, en función de tramos de edad. Por otra parte, socialmente se espera que la integración relacional de la persona en su familia compensará en cada momento las limitaciones en sus capacidades mediante, por ejemplo, cuidados personales o acompañamiento en decisiones. Los servicios sociales actúan para prevenir, compensar o revertir desajustes entre la capacidad de la persona y el soporte de su familia y, por eso, el instrumento valora las situaciones de riesgo y desamparo.

Del mismo modo que la comunidad de conocimiento ofrece este y otros instrumentos para valorar la protección o desprotección de las niñas, niños y adolescentes por parte de sus familias, podemos encontrar muchos otros (más o menos específicos) para diferentes parcelas (mayores o menores) dentro del perímetro sectorial que hemos propuesto: sobre capacidades funcionales para unas $u$ otras actividades de la vida diaria, sobre autodeterminación, sobre habilidades sociales, sobre apoyo social, sobre estructuras familiares, sobre activos y dinámicas comunitarias, y así sucesivamente. Instrumentos aportados desde diversos campos disciplinares y profesionales.

Además, una propuesta conceptual como la de la interacción nos permite ver cabalmente a todas las personas que necesitan el apoyo de los servicios sociales como personas capaces, a su vez, de mejorar en su autonomía funcional y autogestión vital, y de brindar apoyos primarios en cadenas y redes ecológicas de sostenibilidad relacional. Las habilidades sociales que estamos trabajando con un joven se convierten en ejercicio de la parentalidad positiva hacia su hija, que, a su vez, es una relevante fuente de apoyo social para una vecina mayor que vive sola, la cual llama cada tarde por teléfono a su hermano, que vive a 600 kilómetros. Cuando percibimos y diagnosticamos a cada una de esas personas de un modo que nos lleva a extraerlas de esa cadena de interacción, posiblemente estamos invisibilizando y contribuyendo a destruir, en buena medida, el bien que deberíamos proteger y promover, el bien cuyo estado debemos conocer a través de nuestras herramientas de diagnóstico, valoración y evaluación.

Según esta mirada, los servicios sociales no deben poner el foco en la manera en que la discapacidad de una persona afecta (o no) a su empleo, alojamiento o ingresos, sino a su autonomía en las actividades de la vida diaria, al autogobierno de su vida, a sus vínculos familiares o a sus relaciones comunitarias. Que son exactamente los mismos aspectos que interesan a los servicios sociales en el caso de una persona en situación de grave exclusión social (pues de su situación económica, residencial o laboral, en principio, han de ocuparse otros ámbitos sectoriales). En esta línea, el manual Inclúe propone, 
como buena práctica de diagnóstico, "identificar con qué fuerzas y recursos cuentan tanto la persona como su entorno, mapeando la disponibilidad de recursos en todos los 'espacios' físicos y relacionales en los que transcurre la vida de la persona y teniendo en cuenta todos los tipos de recursos disponibles" (Blanco et al., 2015b: 33).

Sin embargo, por ejemplo, el Baremo de Valoración de la Dependencia (BVD) sería, desde este punto de vista, un ejemplo opuesto al de Balora, ya que no toma en consideración la red de apoyo familiar y comunitario de la persona, lo cual parece (lamentablemente) congruente con las carencias y errores de planteamiento detectados en la ley española sobre autonomía y dependencia en relación con el apoyo de los servicios sociales al cuidado primario (Casado, 2017).

En cuanto al instrumento de valoración de la exclusión recogido en el Decreto 385/2013, se ha señalado antes que, en su documentación preparatoria, se asumía el concepto de interacción (autonomía funcional e integración relacional) para establecer qué situaciones de exclusión social corresponden a los servicios sociales. Por otra parte, en el Decreto, se diferencia el criterio 1 (más circunscrito al perímetro que se propone en este artículo para los servicios sociales en torno al par autonomía funcional / integración relacional) del criterio 2 (más relacionado con otros ámbitos, como el laboral, el residencial o el económico), y se propone una fórmula de cuantificación de la valoración. También hay que decir que está siendo algo más utilizado que el instrumento general (por ejemplo, la Diputación Foral de Bizkaia ya lo ha hecho en más de mil ocasiones) [Orbegozo, 2016: 29]. Cabría, señalar, por tanto, que se encuentra más avanzado que el instrumento general en el camino indicado por las consideraciones que apuntábamos para la mejora de éste.

A tenor del análisis realizado en materia de diagnóstico, valoración y evaluación de las necesidades o situaciones sobre las que intervienen los servicios sociales, podríamos completar y concluir este segundo punto diciendo que nos encontraríamos con una agenda de mejora en lo relativo a:

- La aplicación prudente de los instrumentos aprobados (especialmente en el caso de los más nuevos), en función del contexto (capacidades disponibles propias y de otros agentes o sectores afectados), especialmente en los casos en los que, en función del diagnóstico o valoración obtenida, se decide no atender a una persona (al menos, por ejemplo, hasta tener constancia de que es atendida adecuadamente desde el otro nivel asistencial o sector de actividad que se considera pertinente por parte de quien realiza el diagnóstico o valoración).

- La utilización y perfeccionamiento de instrumentos cada vez más y mejor focalizados sobre el objeto de los servicios sociales, que ayuden a una mejor comprensión y abordaje de las necesidades y situaciones, especialmente en la atención primaria.

- La diferenciación (y adecuada interrelación) entre el diagnóstico (o los diagnósticos) a efectos de intervención y la baremación a efectos de reconocimiento de un derecho o asignación de la responsabilidad de atención a una determinada estructura administrativa.

- La dinamización de la comunidad o comunidades de conocimiento (con especial protagonismo de los estamentos académicos e investigadores) en los procesos de fundamentación; elaboración; evaluación de usabilidad, eficiencia, fiabilidad y validez; y mejora de los instrumentos, previendo sistemas diferentes de plasmarlos en una norma jurídica para posibilitar e impulsar su utilización.

\section{Principios, ingredientes y dinámica de los procesos de intervención social}

A la hora de caracterizar la actividad o conjunto de actividades que denomina intervención social y que es típica o característica de los servicios sociales, la exposición de motivos de la ley vasca de 2008 se refiere al: "enfoque de atención, de carácter comunitario, que configuran, persiguiendo el afianzamiento de la responsabilidad pública, la universalidad, la proximidad de los servicios a la ciudadanía y su descentralización; la igualdad y la equidad en el acceso y en la utilización de las prestaciones y servicios; la prevención, la integración y la normalización; la atención personalizada, integral y continua; el carácter interdisciplinar de las intervenciones y la calidad de la atención; la cooperación de los diversos agentes que intervienen en el ámbito de los servicios sociales y, particularmente, en el sistema vasco de servicios sociales; la coordinación del conjunto de las actuaciones públicas y privadas, formales e informales, y la promoción de la participación ciudadana y de la iniciativa social”. En el mismo lugar, se establece "el procedimiento básico de intervención, centrado en la coordinación de caso por parte de la persona profesional de referencia y en la elaboración, cuando corresponda, de un plan de atención personalizada".

La Ley denomina prestaciones técnicas a los ingredientes que componen los servicios, distinguiéndolas de las prestaciones económicas (afectadas, en todo caso, a la finalidad propia de los servicios sociales) y de las prestaciones tecnológicas (productos de apoyo). Las prestaciones técnicas consideradas propias del ámbito de los servicios sociales (como la atención personal o el acompañamiento social) son identificadas en el artículo 15.2. de la Ley y definidas en el anexo III del Decreto de 185/2015 de Cartera de Prestaciones y Servicios del Sistema Vasco de Servicios Sociales.

Analizando con perspectiva los elementos de este modelo de intervención social propuesto en la Ley 
y sus decretos de desarrollo, señalaríamos que, en lo que corresponde a enfoques, principios o perspectivas, participa de una corriente básicamente coincidente en la normativa y literatura sobre intervención social o servicios sociales en nuestro entorno. Así, por ejemplo, Manuel Aguilar et al. (2012: 22) señalan que, en los servicios sociales,

"la proximidad activa hace referencia a la disposición a 'ir a buscar' a las personas en dificultad allá donde se encuentran. Las prácticas de outreach y de trabajo de calle, por ejemplo, son coherentes con esta idea. La proximidad activa conecta con la idea de proactividad, de anticiparse a la demanda que puede no hacerse explícita”.

También el llamado "procedimiento básico de intervención” está en sintonía con los consensos de la comunidad de conocimiento. Así, por ejemplo, en el manual Inclué, se plantea la importancia de "lograr establecer las bases de una alianza dinámica (creación del vínculo) entre la persona y los y las profesionales que la atienden en torno a un proyecto común: el proceso de inclusión social de la persona" (Blanco et al., 2015b: 31). El vínculo entre la profesional y la usuaria para, entre otros resultados esperados, contribuir a la construcción de vínculos primarios por parte de la persona. El ejercicio de un derecho exigible (el derecho a los servicios sociales) que contribuye a que la persona adquiera compromisos de activación para la consecución de resultados que considera valiosos. En el artículo 25.1. del decreto de Cartera, el "incumplimiento reiterado de los compromisos adquiridos en el marco del Plan de Atención Personalizada" figura entre las causas de suspensión del derecho a una prestación o servicio.

Por otra parte, parecen afortunadas la diferenciación entre prestaciones y servicios, la centralidad otorgada a las prestaciones técnicas y la diferenciación entre prestaciones propias y no propias. Resulta un avance significativo que se entienda y se explicite que la alimentación o el alojamiento (o el dinero para adquirir esos bienes) no son prestaciones propias de los servicios sociales, ingredientes característicos de la intervención social.

Ahora bien, aunque la definición de las prestaciones propias constituye un intento loable de operativización de los principios antes evocados, posiblemente, de nuevo, nos encontramos ante un exceso normativo que pretende decretar lo que no ha sido decantado por la comunidad de práctica y conocimiento correspondiente. Valga como muestra el hecho de que en el decreto de Cartera se afirma que el acompañamiento social es "la prestación más genuina y característica de los servicios sociales” y, sin embargo, son muy escasas las referencias de la literatura científica y técnica a dicha prestación en nuestro entorno. Así, según Borja Aguirre (2013: 128), por ejemplo, “en el mundo de la exclusión social [...] no hay muchas referencias al acompañamiento como estrategia central de intervención. Y aún menos pueden encontrarse experiencias concretas de acompañamiento social que eleven la vista sobre su propio trabajo para hacer una reflexión sobre la pertinencia del uso del acompañamiento en estas realidades sociales concretas". Cabe decir que lo que no da la caja negra de las disciplinas y profesiones no lo puede normar la legisladora o la autoridad administrativa.

Por otra parte, si miramos la evolución de otros sectores de actividad, cabe suponer que es grande el recorrido que podrían tener nuestros servicios sociales en la incorporación de productos de apoyo y nuevas tecnologías, lo cual, en principio, podría aportar novedades en términos de empoderamiento individual y diversificación de formas y formatos de relación entre las personas, más allá de la agrupación presencial en un mismo espacio físico (Carretero, 2015).

Sea como fuere, cabe decir que, entre los principios, enfoques o perspectivas de carácter general (comunitaria, preventiva, personalizada, integrada u otras) y esos ingredientes que denominamos prestaciones, apoyos o actividades, hay una franja intermedia que es donde realmente se juega la calidad y eficacia de la intervención social: la de las dinámicas o los procesos interactivos (interdisciplinares e interprofesionales) en los que se van utilizando y mezclando los ingredientes en aplicación de los principios o enfoques mencionados (obviamente, siguiendo el "procedimiento básico de intervención”). Y seguramente, en buena medida, esa franja intermedia es la caja negra de las diversas profesiones y disciplinas de la intervención social. Caja negra en el sentido de que la normativa jurídica puede establecer qué profesional ha de hacer qué cosa (la prestación) y bajo qué requerimientos (los principios), pero no entrar a describir o pretender regular lo que hará.

Al respecto, cabe decir que el cuerpo de conocimiento y tecnología de las disciplinas y profesiones realmente operantes, hoy y aquí, en el ámbito de los servicios sociales y la intervención social aparece, como no podría ser de otra manera, notablemente fragmentado en función de los grandes colectivos para los cuales se han organizado en las últimas décadas los servicios sociales (menores en riesgo o situación de desprotección, personas con discapacidad, personas mayores u otros), y también por disciplinas o áreas de conocimiento académicamente reconocidas. Incluso, en muchas ocasiones, la aplicación de enfoques preventivos, personalizados o comunitarios no consigue romper los muros de esos silos en cuyo interior se represan el saber y la práctica.

Las personas en riesgo o situación de exclusión, por cierto, ni siquiera tienen las estructuras de atención y cuerpos de conocimiento que existen en torno a la infancia desprotegida, la discapacidad o las personas mayores, sino que vienen a constituir el cajón de sastre dentro del cajón de sastre en el que 
encontramos a personas que salieron de la cárcel, personas con adicciones y otros problemas de salud mental, personas que ejercen la prostitución, jóvenes que salieron del sistema de protección, personas sin hogar, miembros de comunidades culturales minoritarias u otras; habiendo, obviamente, entre ellas, personas mayores, en situación de desprotección o con discapacidad.

En ese contexto, aparecen recurrentemente dudas y debates en torno a algunos conceptos (como exigencia, intensidad, cronificación o reducción de daños) que han de abordarse, en todo caso, a partir de la identificación o definición del tipo o abanico de resultados valiosos que está en condiciones de ofrecer la intervención social realmente existente a sus destinatarias y destinatarios, resultados deseados (objetivos) a los que nos hemos referido más arriba.

Desde esa perspectiva, cabe entender la exigencia (baja o alta) como el establecimiento (legítimo e imprescindible), por parte de un servicio, de resultados previamente alcanzados por la persona (por ejemplo, en términos de motivación para el cambio, no uso de la violencia u otros hábitos, capacidades o conexiones), en función de los cuales el servicio se compromete (razonablemente) de cara a la consecución de nuevos objetivos, dentro de procesos o itinerarios razonablemente diseñados (no lineales) y suficientemente flexibles (no rígidos), pues "las intervenciones se dividen u organizan en etapas de menor a mayor estructuración de hábitos, rutinas, tareas, formación -es decir, de menor a mayor autonomía-, fomentando el aprendizaje de habilidades sociales que faciliten la recuperación de las relaciones sociales, familiares o de amigos" (Aguirre, 2013: 128).

Ahora bien, el hecho de que, en un determinado momento, un servicio (y una profesional) pueda (y deba) establecer una determinada exigencia previa para la realización de una intervención y prestación de un servicio no quiere decir que el sistema no disponga de otros servicios o alternativas de atención cuando la persona no alcanza (en ese momento) el umbral exigido. Se habla, por ello, de "baja exigencia" o "bajo umbral", que puede asociarse, aunque no necesariamente tenga que ser así, a una relativa modestia o limitación de los resultados esperados. Entendiendo, lógicamente, que, en el campo de los servicios sociales (como en el sanitario), el mayor éxito posible, en ocasiones, es la cronificación de una situación y que habrá personas que necesitarán apoyos de larga duración y cuya situación de interacción no se aspira tanto a mejorar como a que empeore o se deteriore lo menos posible (reducción de daños). Como se recuerda en el modelo Inclúe (Blanco et al., 2015a: 48):

Junto al de la activación o el de la individualización, otro de los cambios paradigmáticos que se ha producido en los últimos años en el ámbito de las políticas sociales -y, más concretamente, en el ámbito de la salud pública y la atención a las drogodependenciases la extensión de los programas de reducción de riesgos y daños, y el consiguiente desarrollo de programas denominados de baja exigencia o de bajo umbral.

Por otra parte, del mismo modo que no cabe asociar necesariamente baja exigencia con modestia de los resultados esperados (de los objetivos) en términos de cambios en la situación de la persona (pues partiendo de una baja exigencia se pueden obtener cambios importantes), tampoco se ha de asociar baja exigencia o reducción de daños con baja intensidad de la intervención social. Puede haber intervenciones de baja exigencia y alta intensidad y también, lógicamente, intervenciones de alta exigencia y baja intensidad, y todas ellas, lógicamente, pueden ser más breves o de más larga duración (Ruiz y Beteta, 2016: 46).

Esta comprensión de la exigencia en términos de resultados previamente alcanzados, necesarios en un momento del proceso, y la concepción del proceso de intervención social como un itinerario individual, personalizado y flexible, con diversas alternativas y ritmos posibles (y también tiempos de permanencia en la misma situación o de regreso a situaciones anteriores) al que la persona tiene derecho, contrasta con la interpretación de la exigencia en términos de contraprestación o condicionalidad (McNeil y Hunter, 2015: 21), en modelos de atención en los que se entiende que la persona ha de hacer merecimientos para recibir determinada atención (no tiene derecho a ella, por tanto) y la intervención social (como otras) se entiende y practica (y se desvaloriza) en términos de control obligatorio al que se somete la persona bajo la amenaza punitiva de retirarle determinadas prestaciones. Al respecto, se ha dicho que:

Mientras que en servicios como los sanitarios y sociales se ha producido una tendencia a alentar a las personas usuarias a que se apropien más de los servicios y a ejercer la elección y el control, los grupos desfavorecidos han tenido cada vez más metas y resultados fijados por una autoridad central con medidas punitivas por incumplimiento. En los programas de apoyo [...] observamos cómo en la última década las personas adultas socialmente excluidas han estado cada vez más sujetas a mecanismos como el pago por resultados [...]. Aquellos que viven con múltiples problemas tienen la mayor percepción de lo que les permitiría cambiar sus vidas, y sus aportes deben buscarse en el establecimiento de sus metas de atención y en el diseño de los servicios que utilizan, al igual que para otros grupos que usan servicios de salud y sociales. La implicación, sin embargo, se interpreta a menudo en su sentido más estrecho [...]. En términos más generales, al salir de los servicios, las oportunidades estructuradas para el apoyo continuo de iguales y las rutas hacia la participación, la capacitación y el empleo son 
incompletas, a pesar de la creciente evidencia de la importancia de los lazos sociales y la actividad significativa para sostener mejoras obtenidas como resultado del apoyo profesional (McNeil y Hunter, 2015: 32).

Por el contrario, programas y propuestas como Vivienda Primero (Housing First) o enfoques de "activación inclusiva" en clave de "doble derecho" a la garantía de ingresos y a servicios de apoyo para la inclusión laboral y en otras dimensiones (Zalakain, 2013: 199) están contribuyendo a cuestionar esas visiones de la exigencia en términos de condicionalidad o contraprestación. Como recuerda Fabio Colombo, "a pesar de los avances teóricos en la consideración del sinhogarismo como causado tanto por factores residenciales como sociales, las políticas y servicios para el sinhogarismo están todavía principalmente concebidas como servicios sociales para tratar problemas individuales de personas sin hogar, como enfermedad mental o adicción a sustancias. Vivienda Primero vino a desafiar a este enfoque, reclamando el derecho al alojamiento como su primer principio, y la casa como el principal servicio a proveer a las personas sin hogar, sin condicionarlo a la participación en otros servicios de tratamiento" (Colombo, 2016: 16). Recordemos a este respecto que en el País Vasco se aprobó por ley en 2015 “el explícito reconocimiento del derecho subjetivo de acceso a la ocupación legal de una vivienda por todos los que no se hallen en posesión de una y no dispongan de medios necesarios para conseguirla".

Además, la emergente y creciente aplicación de los enfoques comportamentales (behavioural insights) y de las ciencias del comportamiento al campo de las políticas públicas está ofreciendo abundante evidencia acerca del valor y efecto de (frecuentemente pequeños) estímulos o incentivos, y sobre los costes y efectos no deseados de las condicionalidades y contraprestaciones en los servicios de bienestar. "El foco en las personas usuarias es habitualmente a través de 'empujoncitos' [nudges], esto es, intervenciones que orientan a las personas en una determinada dirección a la vez que preservan su libertad de elección” (OCDE, 2017: 49).

Hay que entender, en cualquier caso, que es la persona (el individuo) la destinataria de los servicios sociales de los que estamos hablando. Es la situación de interacción del individuo (su autonomía funcional e integración relacional) la que nos dará la medida de la intervención social, sobre cuya intensidad, exigencia o duración estamos haciendo consideraciones. A partir de ahí, nos encontraremos con tres tipos de intervenciones:

- Intervenciones necesariamente individuales.

- Intervenciones que pueden hacerse de forma individual o colectiva en función de consideraciones organizativas o económicas (que abordaremos más adelante), pero que no se resienten por ello en términos de proceso y resultados.
- Intervenciones necesariamente colectivas.

Germán Jaraíz y Auxiliadora González (2014: 154) consideran "necesario un refuerzo de enfoques de intervención colectiva [...] orientados a activar resiliencias individuales y colectivas". Ello sería coherente con las perspectivas críticas que alertan al trabajo social -y en general, a la intervención social-contra el olvido de los factores y consecuencias estructurales de las situaciones de las que nos ocupamos y de las intervenciones que realizamos, señalando que "se hace preciso, en primer lugar, desencantar la profesión, asumir que no posee una esencia que la haga per se transformadora, y centrarse en el análisis de los contextos, los usos, los significados y los efectos de las intervenciones concretas" (García y Rendueles, 2017: 244).

Por lo mismo, evidentemente, no puede recibir la misma consideración aquella intervención colectiva en la que la colectividad es de carácter comunitario (es decir, es una colectividad que existe o se puede mantener mediante relaciones primarias entre las personas) que aquella colectividad generada por el propio servicio a los efectos de realizar la intervención.

De otro lado, en los casos en los que la dinámica de prestación de un servicio genera colectividad o agrupa a personas, no hay, de entrada, por qué suponer que todas las personas usuarias de un servicio coincidirán en cuanto, por ejemplo, la exigencia o la intensidad de la atención que reciben. Puede haber servicios que, como tales, estén caracterizados por un determinado nivel de exigencia o intensidad, pero puede haber otros en los que diferentes usuarias reciban atención con diferentes grados de exigencia o intensidad, lo cual parece más coherente con la personalización y flexibilidad de la que estamos hablando y, sin embargo, contradice la previsión de nuestro marco normativo de clasificar los servicios en función de su intensidad y de colocarlos, por ello, en diferentes niveles asistenciales (y manos institucionales).

En función de sus capacidades técnicas y profesionales instaladas en el sistema y los servicios, y en función de los recursos y activos presentes en las personas y comunidades, los servicios sociales han de ir jugando sus bazas. Históricamente hemos jugado más la baza de la intensidad (horas) de prestación profesional de menor valor añadido (llegando frecuentemente a atención directa de personal menos cualificado de $\mathbf{2 4}$ horas al día, siete días a la semana en internamiento asilar), sacrificando la personalización cualificada y la proximidad comunitaria.

Sea como fuere, desde la regulación normativa y la planificación política se ha de reconocer y respetar la esfera de las redes y comunidades de conocimiento (especialmente las de las disciplinas y profesiones). Las personas con responsabilidades 
políticas y técnicas en los poderes y administraciones públicas pueden y deben potenciar las dinámicas del conocimiento y participar en ellas de forma activa y con provecho, pero cometen un error si permiten que la lógica política, administrativa o institucional suplante o pervierta la lógica del conocimiento. Una es la lógica y la dinámica que conduce a aprobar una ley o un decreto, y otra, la que permite establecer un protocolo de intervención o evaluar un servicio.

\section{Itinerarios, segmentación, especialización e integración vertical}

Tras el repaso crítico a la concepción del objeto de nuestros servicios sociales (las necesidades o situaciones a las que han de dar respuesta); a los conocimientos e instrumentos que tenemos para diagnosticar, valorar o evaluar dichas necesidades o situaciones; y a la dinámica de los procesos de intervención social que nos permiten responder a (u obtener resultados en relación con) esas necesidades o situaciones; corresponde ahora examinar algunos aspectos del modelo de organización interna del sistema público de servicios sociales.

La normativa establece que, en principio, accederíamos al sistema a través de los servicios sociales de base (entendidos como parte de la atención primaria) dirigidos, en principio, a toda la población de un determinado territorio. Pediremos una cita individual o familiar, o participaremos en alguna actividad colectiva organizada desde el sistema. También podrá suceder que accedamos al sistema, excepcionalmente, a través de un servicio de urgencias. En función de nuestra necesidad o situación, podremos ser orientadas o derivadas, en su caso, a un servicio de atención secundaria. Lo que señalan diferentes informes es que las personas en situación de exclusión social, en un número considerable de ocasiones, no acceden al sistema mediante (o gracias a) la atención primaria (SIIS Centro de Documentación y Estudios, 2015: 15), lo cual ocurrirá seguramente con otros de los colectivos atendidos tradicionalmente por los servicios sociales, como el (o los) de las personas con discapacidad.

Según el modelo que adopta la Ley vasca de Servicios Sociales, los servicios son agregados estables de prestaciones y otras actividades que se ofrecen a un determinado segmento o perfil (más amplio o más restringido) de potenciales destinatarias. Cabe señalar que hay servicios que se prestan en una sede física propia a la que acude o en la que permanece la persona usuaria (como, por ejemplo, los de carácter ambulatorio, diurno, nocturno y residencial) y otros en los que eso no sucede (como, por ejemplo, los de carácter domiciliario, virtual y callejero o de medio abierto). Mirado desde el punto de vista del itinerario de la persona, sólo tiene sentido preguntarse por si ubicaremos un servicio en la atención primaria o secundaria en el caso de los servicios con sede física. Dado un diseño de los servicios (en términos de agregación sinérgica de prestaciones y profesionales, y de perfil adecuado de destinatarias), podremos colocar en el nivel primario (de mayor proximidad a los domicilios de las personas) aquellos servicios que resulten más numerosos y deberemos ubicar en el nivel secundario (con menor proximidad) los que resulten menos numerosos. En el caso de la Ley vasca, sin embargo, se aplica la clasificación y ubicación en uno u otro nivel asistencial a todos los servicios.

En cuanto a la especialización, ésta puede tener que ver con construir más conocimiento sobre situaciones que afectan a menos personas, pero no siempre es así. Por ejemplo, saber más sobre intervenciones preventivas de carácter poblacional es una vía de especialización en la que no se verifica la regla de que una mayor especialización reduce el número de potenciales destinatarias (y viceversa). En concordancia, la Ley vasca de Servicios Sociales afirma que puede haber especialización en primaria y en secundaria.

Pues bien, del mismo modo que los servicios sociales se han inspirado en la sanidad para crear estos niveles de atención, pueden inspirarse en las propuestas y prácticas sanitarias de reforzamiento de la atención primaria (de construcción de una atención primaria cada vez más resolutiva) y de integración vertical (entre primaria y secundaria) liderada por la primaria y apoyada en el conocimiento y la tecnología. Como recuerdan Vicente Ortún-Rubio y Guillem López-Casasnovas (2002: 7), “cuando el conocimiento gana importancia como factor productivo y la demanda se sofistica, aumenta la necesidad organizativa de situar la capacidad decisoria allá donde está la información específica y costosa de transmitir: aumenta la necesidad de descentralización”. Esto sucede con especial motivo si abogamos por unos servicios sociales dedicados a la interacción y, específicamente, a la integración comunitaria. Si bien una cirujana cardiovascular puede repararnos una válvula mitral lejos de nuestro entorno comunitario (originario o escogido), no parece posible que un educador social nos ayude a reconstruir red comunitaria lejos de dicho entorno, por intensa y especializada que haya de ser su labor.

La OCDE (2015: 16) adapta y adopta una definición de la integración (tanto la vertical, intrasectorial, de la que hablamos ahora, como la horizontal, intersectorial, a la que nos referiremos más adelante) como "un conjunto coherente de métodos y modelos relativos a los niveles de la financiación, la administración, la organización, la prestación de servicios y clínicos diseñados para crear conectividad, alineamiento y colaboración dentro de (y entre) diferentes sectores".

En el caso del País Vasco, en un reciente informe de la Defensoría del Pueblo (Ararteko, 2016: 98), "se hace referencia al concepto de 'doble llave', es decir, al hecho de que - tal y como señalan la Ley de Servicios Sociales y el decreto de Cartera- 
el acceso a los recursos de atención secundaria dependa exclusivamente de los criterios de los responsables de tales recursos en la administración foral, independientemente del criterio de las personas que en el ámbito de la atención primaria han gestionado el caso". Si, además, hemos dicho antes que las 'llaves' (los instrumentos de diagnóstico, valoración y evaluación) jurídicamente normativizadas (más rígidas, probablemente) tienen margen de mejora, entre otros aspectos, en la eficiencia, nos encontramos, probablemente ante un cuello de botella o agujero negro especialmente contrario a la continuidad y eficacia de la atención, en ausencia, por otra parte, de los "protocolos de derivación entre los niveles de atención primaria y secundaria”, cuyo diseño el artículo 34 del decreto de Cartera encomienda al "Gobierno Vasco, en el ejercicio de sus competencias de coordinación con las demás administraciones públicas vascas, y con la colaboración e informe favorable del Órgano Interinstitucional de Servicios Sociales".

Por otro lado, la exposición de motivos de la Ley vasca de Servicios Sociales afirma que "de conformidad con las formulaciones más avanzadas en la materia, se ha optado por establecer un sistema de respuesta a las necesidades en función de la naturaleza y características de estas últimas, en lugar de estructurarlo atendiendo a los diferentes colectivos". Sin embargo, en el artículo 22, en los servicios de atención secundaria del catálogo, especialmente en los residenciales, reaparecen, no ya las tres o cuatro 'contingencias' antes referidas, sino, en número mayor, algunos de los mencionados 'colectivos':

- Centros residenciales para personas mayores.

- Centros residenciales para personas con discapacidad.

- Centros residenciales para personas con enfermedad mental.

- Centros residenciales para personas menores de edad en situación de desprotección.

- Centros residenciales para personas en situación de exclusión y marginación.

- Centros residenciales para mujeres víctimas de maltrato doméstico y otros servicios residenciales para mujeres.

Sin embargo, no necesariamente se comprende qué aporta la clasificación y agrupación de las personas en ese tipo de colectivos para su participación en procesos de intervención social. Y parece evidente que, en los actuales servicios sociales, la limitada oferta efectiva de servicios sociales de atención primaria para (probables o presuntos) miembros de dichos 'colectivos' incrementa nuestra probabilidad de ser clasificadas dentro de alguno de ellos y, dadas las circunstancias, alejadas de nuestros (u otros) entornos comunitarios.

La personalización (atención centrada en la persona) necesita superar ese tipo de segmentación obsoleta por grandes 'colectivos', que funcionan en gran medida como 'pasaporte' para un itinerario segregado estándar (a veces, literalmente, de la cuna a la tumba, como en el caso de no pocas personas con discapacidad intelectual, por ejemplo), e ir avanzando en procesos de microsegmentación que generen diversidad de itinerarios protocolizados y flexibles, en los que los servicios funcionen menos como lugar en el que estar y más como proveedores y activadores de apoyos cada vez más autogestionados, comunitarios y capaces de atender a la diversidad sexual, generacional, funcional y cultural.

Los 'colectivos' tradicionales, en su caso, podían constituir una segmentación (relativamente) coherente con una asistencia social residual orientada al control social institucionalizado en una sociedad tradicional (de pleno empleo, patriarcal, con unas contingencias excepcionales gestionables por la Seguridad Social contributiva y comunidades tradicionales relativamente homogéneas): menores desprotegidas por 'fallo' del mecanismo 'familia', personas con discapacidad 'no aptas' para el mecanismo 'empleo', personas mayores (ya) 'no aptas' para el 'empleo' sin mecanismo 'familia' que se haga cargo y un resto que, como ya hemos señalado, incluso entre los 'colectivos' clásicos (como los mencionados en el catálogo de la Ley vasca), se forma por exclusión (dentro de la exclusión), con líneas divisorias generadas frecuentemente por el propio sistema de políticas públicas: administrativas (personas inmigrantes), sanitarias (personas con enfermedad mental o con adicciones), penitenciarias (personas que salen de la cárcel), de seguridad (diferentes tipos de víctimas), de garantía de ingresos (personas pobres), de vivienda (personas sin hogar) o de los propios servicios sociales (personas jóvenes egresadas del sistema de protección de menores).

Sin embargo, estos 'colectivos' tradicionales resultan totalmente obsoletos, inadecuados y disfuncionales como criterio de segmentación para unos servicios sociales universales que pretendan proteger y promover la interacción de todas las personas con una orientación personalizada, preventiva, comunitaria y poblacional en una sociedad del conocimiento, del riesgo, del bienestar y de la complejidad; una sociedad en la que se diversifican tanto los ejes de fragmentación y exclusión social como las vías de empoderamiento e inclusión; una sociedad que demanda una intervención social capaz de potenciar los activos individuales y los vínculos comunitarios. Como señala Manuel Aguilar (2014: 26):

[La] limitada capacidad de focalizar la acción sobre objetivos estratégicos, estratificar poblaciones y dimensionar respuestas en función de grados de necesidad, así como de dar un papel más activo a las propias personas usuarias es especialmente intensa en el nivel primario, precisamente allí donde es más necesaria. En buena medida se explica por lo que podríamos denominar un déficit cognitivo del sistema, que 
nace de una muy débil conceptualización de los tipos de situaciones, necesidades y demandas sobre las que interviene.

Nos encontramos, por tanto, con una atención primaria con limitada capacidad preventiva y de gestión de la diversidad (de género, generacional, funcional y cultural), y con incentivos perversos para derivar a servicios pretendidamente especializados en función de una segmentación obsoleta, que agrupa a las personas pertenecientes a unos supuestos colectivos, sin que se justifique que dicha agrupación tiene alguna razón de ser en términos de intervención y cuando (en general, salvo a efectos de empoderamiento, en algunos casos, cuando es deseada por las propias personas) la literatura la desaconseja en aras del enfoque comunitario e inclusivo, y con una casi total ausencia de itinerarios, especialmente itinerarios cuya trazabilidad (las migas de pan de Hansel y Gretel o el hilo que Ariadna deja a Teseo) facilite recorrerlos de regreso a la comunidad una vez que hemos sido alejadas de ella.

Cada uno de los colectivos, contingencias o, en general, criterios de segmentación utilizados en servicios sociales, especialmente si conduce a la agrupación de personas como usuarias, en un mismo momento y lugar, de un determinado servicio, debe ser puesto en cuestión y, en todo caso, visto, en principio, como un paso de un proceso o itinerario en el que la persona tenga la oportunidad de transitar a situaciones y servicios en los que encuentre la diversidad de relaciones y personas que se da en la comunidad. Pensemos en el caso de una persona con enfermedad mental que accede al sistema de servicios sociales en el marco de una atención integrada liderada desde sanidad y que lo hace, en un primer momento, en un 'centro residencial para personas con enfermedad mental' realmente existente y que esté admitido ese criterio de segmentación (propio de otro ámbito sectorial) en los servicios sociales, como lo está ahora. Entenderíamos que el itinerario de elección sería, en principio, el que llevara a esa persona cuanto antes a ser atendida en los servicios sociales desde un servicio no residencial y que no utilizara la enfermedad mental como criterio de segmentación (un servicio que, en la organización actual, sería un servicio de atención primaria).

El propio diseño de los servicios que recogen las fichas del decreto de Cartera (centrándonos ahora en lo que se refiere más explícitamente a la exclusión e inclusión social) ha sido objeto de críticas, en la medida en que puede haber alternativas o combinaciones necesarias (por ejemplo, en términos de perfil de usuarias, proximidad, exigencia, intensidad, duración u otros aspectos, como el carácter ambulatorio o callejero de los servicios) que no se contemplan (Duque, 2014: 41-42; SIIS Centro de Documentación y Estudios, 2015: 27). En lo que tiene que ver con la inclusión y la exclusión social (o su riesgo), los servicios de atención primaria (por las características de los diurnos, nocturnos y residenciales y por las restricciones o indefinición del resto) no parecen diseñados para dar soporte a las personas, posibilitando que no necesiten servicios de atención secundaria o tras hacer uso de los servicios de atención secundaria.

Sea como fuere, hay que señalar que estas fichas son el fruto de un diseño técnico tentativo (en principio, obligatoriamente revisable a los dos años) cocinado después a fuego muy lento en un prolongado proceso de negociación política, condicionado por el hecho de que los niveles asistenciales (atención primaria y atención secundaria) corresponden a instituciones diferentes.

De hecho, el artículo 12.5. del decreto de Cartera afirma que se:

Favorecerá, siempre que resulte idóneo, el acceso a la alternativa 0 alternativas de atención que posibiliten, en mayor medida, la permanencia de la persona usuaria en su entorno habitual, siempre que ésta sea su elección, justificando[se, en su caso,] la no adecuación de una fórmula de atención más susceptible de garantizarla, según lo previsto en el artículo 25.1, letra c, de la Ley de Servicios Sociales. De este modo, promoverá que las personas: a) ejerzan el poder de decisión sobre su propia existencia, eligiendo su lugar de residencia y dónde y con quién vivir, sin verse obligadas a vivir con arreglo a un sistema de vida específico; b) y gocen de su derecho a vivir en su comunidad, en igualdad de condiciones y opciones, y a su plena inclusión y participación activa en la misma, evitando su aislamiento o separación de ésta. A tal efecto, facilitará que las personas dispongan de apoyos formales (de entre los servicios y/o prestaciones económicas previstos en la Cartera de Prestaciones y Servicios a los que tengan derecho) para desarrollar las actividades de la vida diaria y mantener, recuperar o aumentar, en lo posible, su autonomía”.

El artículo 12.6. del mismo Decreto dirá que “los servicios de la Cartera de Prestaciones y Servicios constituyen un conjunto de apoyos formales que podrán compatibilizarse entre sí a fin de ofrecer un apoyo integral y adaptar la intervención a las necesidades, capacidades y, en lo posible, preferencias de cada persona, así como a las características de su contexto. Asimismo, en la determinación del recurso, o combinación de recursos más idónea y, en coherencia con el modelo comunitario, se adoptarán enfoques de prevención y promoción de la autonomía, y participación y calidad de vida en la comunidad”. Y señalará el artículo 12.7 que "a tal efecto, el o la profesional de referencia, con la participación de la persona y/o familia usuaria, seleccionará, de entre los servicios y/o prestaciones económicas de la Cartera de Prestaciones y Servicios a los que las personas puedan tener derecho, aquel recurso o combinación de recursos más adecuada para facilitar, cuanto sea posible, su inclusión social y el desarrollo de sus proyectos vitales, y hacer 
efectivo un grado satisfactorio, en cada caso, de participación activa, vida independiente y autonomía personal en el seno de la comunidad".

Recordaremos, por último, que el artículo 13 del decreto de Cartera, que trata sobre "flexibilización de los requisitos de acceso y permanencia en los servicios", establece que:

1. Las administraciones públicas vascas, por sí mismas o mediante acuerdos entre sí, podrán flexibilizar los requisitos de acceso y permanencia en los servicios, estableciendo en dichos acuerdos, si se alcanzan, la oportuna compensación económica a favor de la administración titular del servicio cuyas condiciones se han flexibilizado.

2. Dichas fórmulas de flexibilización: a) se orientarán siempre a facilitar el continuo de atención y el uso de las alternativas de atención más integradas en el medio comunitario y, por tanto, una atención más personalizada, integral y próxima; b) se podrán adoptar siempre que resulten idóneas para responder a las necesidades $y$, en lo posible, a las preferencias de la persona atendida, requiriendo su adopción tanto la prescripción técnica como la conformidad de la persona atendida.

Hoy por hoy, parecemos estar lejos de ese escenario deseable y contamos más bien con un conjunto no del todo coherente y articulado de servicios, de carácter más bien tardíamente reactivo y más bien paliativo, por los que determinadas personas en situación de exclusión social van aprendiendo (a veces perversamente) a circular de manera frecuentemente desordenada, reiterativa e ineficiente (Duque, 2014: 41; SIIS Centro de Documentación y Estudios, 2015: 23-25).

En palabras de Rafael López-Aróstegui (2016: 22), "asentar y reforzar los servicios sociales municipales y los servicios sociales de base es fundamental para desplegar el modelo comunitario y posibilitar un equilibrio adecuado entre niveles de atención (primaria y secundaria) que mejorará la eficacia y la eficiencia del Sistema Vasco de Servicios Sociales a medio plazo". La agenda, por tanto, parece clara y urgente en este momento: incrementar la potencia y versatilidad de los servicios sociales de proximidad, posiblemente mediante el enriquecimiento de las características y potencialidad de los servicios sociales de atención primaria con recursos y capacidades procedentes de servicios sociales de atención secundaria (no sólo, desde luego, de los destinados a personas en situación de exclusión social); y evaluar su eficacia y eficiencia para abordar las situaciones de forma cada vez más preventiva y comunitaria y, consiguientemente, para disminuir el uso de los servicios de atención secundaria. Las experiencias de utilización del mismo equipamiento por parte de servicios sociales de atención primaria y secundaria analizadas por Jon Iribar (2017) representan un punto de partida.

\section{Integración intersectorial entre los servicios sociales y otros ámbitos de actividad}

Es evidente que la operación de sacar a los servicios sociales de un posicionamiento residual y reactivo en un pretendido y crecientemente inmanejable nicho de actividad dedicado al abordaje de las situaciones de complejidad y exclusión social tiene sentido en el marco de un proyecto de construcción de una nueva respuesta a dichas situaciones, respuesta que, dentro de un modelo de políticas sociales sectoriales universales (como sanidad, educación, servicios sociales, empleo, vivienda y garantía de ingresos), necesariamente habrá de ser intersectorial.

En los artículos 45 y 46 de la Ley vasca de Servicios Sociales, con especial referencia a la interfaz entre servicios sanitarios y servicios sociales, se plantea una doble vía de abordaje de este reto:

- La existencia de servicios que, perteneciendo a un determinado sistema sectorial (servicios sociales, sanidad u otros), incorporan una cierta cantidad e intensidad de prestaciones típicas de otros ámbitos sectoriales.

- La facilitación de los itinerarios de las personas a través de diversos ámbitos sectoriales.

En la actualidad, el paradigma que se va imponiendo internacionalmente al respecto (OCDE, 2015) es el de la atención integrada, coincidente con el propuesto por la Ley vasca, en el sentido de que no trata de deconstruir los ámbitos sectoriales ni de crear 'espacios' intermedios entre sectores, sino que aboga por:

- Identificar proactivamente a las destinatarias de la atención integrada mediante sistemas preventivos de diagnóstico, valoración, evaluación y cribado de la complejidad social, en función de criterios de segmentación o estratificación.

- Protocolizar itinerarios tipo (o establecer estrategias compartidas) para dichos segmentos o perfiles poblacionales; itinerarios que sean flexibles para adaptarse personalizadamente a las características y preferencias individuales.

- Generar, en su caso, servicios integrados (con prestaciones y profesionales propios de diferentes ámbitos sectoriales).

- Cuidar la continuidad de la intervención y los itinerarios intersectoriales, especialmente en momentos delicados de transición entre ámbitos: cuando recibimos el alta sanitaria y hemos de ser atendidas por los servicios sociales, cuando salimos del sistema educativo y nos incorporamos a un empleo, y así sucesivamente.

- Construir la atención integral mediante la integración intersectorial, desechando, salvo casos excepcionales, que una persona reciba una atención integral por parte de uno de los ámbitos sectoriales. 
- La necesidad de trabajar la integración intersectorial en el nivel macro (con expresión presupuestaria), en el nivel meso (con gestión resolutiva) y en el nivel micro (de modo que la persona no note las 'costuras').

- Simplificar los procesos e itinerarios intersectoriales mediante la interoperabilidad (con los denominados ‘bus de integración’ o ‘hub de integración') entre sistemas de información diferentes, que ahorra costes de transacción, sin descartar sistemas presenciales e intensivos en capacidades profesionales, como la gestión de casos.

En lo relativo al diagnóstico, valoración y evaluación de necesidades y situaciones para su atención integrada, hay que referirse a instrumentos pensados para diversos perfiles poblacionales portadores de necesidades complejas atinentes de forma simultánea a varios sectores de actividad, e incluso a intentos de establecer métricas para el resultado global de las políticas sociales, en términos de calidad de vida, bienestar, inclusión social o felicidad. Aquí el camino por recorrer es enorme, como indican los trabajos del Institut Universitari Avedis Donabedian con las instituciones catalanas para la identificación de necesidades sociales complejas (donde se ha escogido la Self Sufficiency Matrix) o, en el caso vasco, el trabajo liderado por Elena Elosegui para Etorbizi en relación con un instrumento de valoración (InterRAI-CA) para el inicio de un itinerario de atención integrada por parte de sanidad y servicios sociales.

En unas conversaciones intersectoriales recientes impulsadas por la European Anti Poverty Network del País Vasco (EAPN-Euskadi), hemos constatado que, en determinados lugares de nuestro entorno, se han producido algunos avances en prácticas intersectoriales, frecuentemente a partir de riesgos o situaciones de emergencia o conflicto social, o, en otras ocasiones, como respuesta a la complejidad o gravedad de determinadas situaciones. Se trata de iniciativas diversas, como planes, estrategias, programas, protocolos, mesas, observatorios, consorcios o equipos. Unas veces, estas iniciativas tienen un carácter más multilateral; y otras, uno más bilateral (por ejemplo, entre educación y servicios sociales, o entre servicios sociales y sanidad). Se pueden concitar en torno a determinadas cuestiones (por ejemplo, violencias machistas, sinhogarismo, absentismo escolar, desescolarización, acoso escolar o convivencia vecinal) o colectivos poblacionales (como infancia o mayores). Varía el ámbito geográfico (más grande o pequeño) de las iniciativas. En ocasiones, se vinculan a la gestión de conflictos (con experiencias de mediación); otras veces, a la gestión de casos; otras, a zonas de intervención especial. Existen, por otra parte, herramientas para la atención integrada con rango legal, como es el Consejo Vasco de Atención Sociosanitaria o, en general, las estructuras de soporte de políticas transversales (como las relacionadas con la igualdad de género, la infancia y adolescencia, o la familia, por poner tres ejemplos). Aparte están, por supuesto, todas las que se vinculan, explícitamente, con la propia política pública de inclusión social.

Sin embargo, la valoración de estas iniciativas de encuentro intersectorial es que tienen, en muchos casos, un corto o limitado ciclo de vida útil y, por otra parte, parece posible que ya se estén produciendo ciertas duplicidades, disfunciones e ineficiencias. Como claves de mejora, se apuntan las siguientes:

- Plantear marcos de colaboración de todos los sectores (o tantos como sea posible), como encuadre para las iniciativas que vinculen sólo a dos 0 a tres de ellos.

- Apostar por marcos de colaboración cuyo ámbito o escala territorial y poblacional ofrezca masa crítica suficiente y abordable para la mejora de la pertinencia y la eficiencia de la acción pro bienestar, mediante la atención integrada; y que los marcos mayores y menores se conecten a estos marcos intermedios, ofreciéndoles contexto e impulso (los mayores), y operativización y retroalimentación (los menores).

- Superar cuanto antes, sobre la base del conocimiento, la fase de reuniones abiertas y amplias de coordinación entendidas como presentación interpersonal y entrega recíproca de información sobre el trabajo de cada sector, para entrar en dinámicas planificadas por objetivos y estructuradas por procesos.

Por otra parte, como se ha dicho, es aconsejable que en el sector de los servicios sociales (como en todos los demás) pueda haber servicios integrados en los que la presencia de prestaciones de otros ámbitos (como el alojamiento, por ejemplo) contribuya a incrementar su capacidad de ser relevantes en itinerarios de abordaje de la complejidad y la exclusión social; y especialmente útiles en escenarios en los que otros sectores (como el de la vivienda, por ejemplo) estén demorándose en asumir sus responsabilidades en el marco de una política general (o, al menos, transversal) de inclusión social. Se entiende que los servicios sociales integrados serán de elección, en la medida en que en el plan de atención individual personalizado de la usuaria sean más relevantes las prestaciones, apoyos o actividades relacionados con el autocuidado, la autodeterminación, y las relaciones familiares y vínculos comunitarios (tales como, por ejemplo, asistencia personal, representación, mediación u otros).

También es cierto que, en ocasiones, el hecho de que entidades de la iniciativa social o privada puedan concertar o contratar servicios en diferentes ámbitos sectoriales puede contribuir a la continuidad e integración de la atención. Sin embargo, ni los servicios sociales integrados ni el aporte de la iniciativa social o privada pueden verse como la clave del éxito en la integración intersectorial, que descansa más bien, según el modelo de referencia, en el compromiso equiparable y colaborativo de todos los 
sectores de actividad en el abordaje de la complejidad y la inclusión social, potenciando las sinergias entre los bienes (como salud, conocimiento, interacción, empleo, alojamiento o subsistencia) de los que se ocupa cada una de las ramas que contribuyen al bienestar e inclusión social.

Por otra parte, en el sistema vasco de servicios sociales la ausencia, todavía, del sistema vasco de información sobre servicios sociales al que nuestra Ley dedica todo el capítulo II del título IV (artículo 79) es, sin duda, una carencia de primera magnitud para la integración de la atención (además, obviamente, de afectar de otros modos al valor de los resultados que nuestros servicios sociales pueden ofrecer a la ciudadanía).

Sea como fuere, un escenario de este tipo obliga a los servicios sociales a deshacerse cuanto antes de cualquier pretensión, rezago o tic de una presunta transversalidad o, en su caso, pretensión de centralidad, dado que, entre los diversos perfiles de casos complejos, habrán de ser diferentes los liderazgos y, en todo caso, cada sector habrá de legitimarse por su aportación específica y reconocible de valor a la persona, y por su capacidad de integrarse con el resto. En algunos casos, lo primero será la vivienda; en otros, el empleo; en otros, la interacción; en otros, la salud; en otros, los ingresos; y así sucesivamente. Como ha observado Manuel Aguilar (2014: 2), especialmente en la crisis de los últimos años, "las situaciones de dificultad económica (pobreza, pérdida de vivienda...) han crecido de forma espectacular y fluyen hacia los servicios sociales, a los que se les supone una función de última red de protección para la que no están diseñados”.

Puede haber servicios (como los de cuidado infantil u ocio juvenil, por poner dos ejemplos) que se incorporen dentro del perímetro de los nuevos servicios sociales, a la vez que éstos reclaman a los servicios de vivienda el liderazgo en el abordaje del sinhogarismo; 0 a los educativos, el liderazgo frente al absentismo escolar; 0 al sistema sanitario, el liderazgo en salud mental y adicciones; 0 a la política de garantía de ingresos, el liderazgo en lo que tiene que ver con la pobreza económica; o a los servicios de empleo, el liderazgo en la atención a las personas que encuentran más dificultades para encontrar ocupación remunerada.

A la vez, el conocimiento recíproco entre sectores que proporcionan las dinámicas de atención integrada debe ayudar a identificar en otros sectores oportunidades valiosas para las personas. Pensemos, por ejemplo, en la importancia de las bibliotecas para las personas sin hogar (responsabilidad, en principio, de los servicios de vivienda). 0 la del servicio doméstico para la vida de las personas con limitaciones funcionales en su domicilio (responsabilidad, en principio, de los servicios sociales). 0 la de los servicios sociales para la prevención de la violencia de género (responsabilidad, en principio, de la Policía).
La construcción del nuevo perímetro de los servicios sociales debe hacerse de forma proactiva, en todo caso, pues los otros sectores tienen fuertes incentivos para desentenderse de determinados casos complejos que históricamente han sido considerados propios de los servicios sociales. Como señala Manuel Aguilar (2014: 22), “una inadecuada delimitación del campo crea dificultades de trabajo no sólo en su interior (qué nos corresponde y qué no nos corresponde hacer), sino sobre todo dificultades graves de coordinación y cooperación con otros pilares". Obviamente, ese escenario de atención integrada intersectorial de la complejidad social está por construir y será especialmente costoso de construir, posiblemente, en lo tocante a la exclusión social. Por ello, desde un criterio ético, los servicios sociales no pueden abandonar, sin más, su tradición histórica de abordaje de ciertos casos complejos sin antes construir la respuesta integrada.

Como señala la OCDE (2015: 204):

Un reto sustancial final para el compromiso significativo a largo plazo en la prestación de servicios integrados es la débil base de evidencia en cuanto a sus efectos en los resultados del uso de servicios y los retornos de la inversión. De hecho, varios países de la OCDE han establecido nuevos métodos de prestación de servicios, que son esencialmente formas de integración, pero no los han reconocido como tales. Para construir una base más sólida para la elaboración de lecciones dentro y fuera de los países de la OCDE, es imperativo que se hagan esfuerzos para evaluar y difundir los hallazgos en cuanto a la eficacia y eficiencia de los servicios integrados.

\section{La red de agentes en los procesos de intervención social}

Si estamos sosteniendo que una nueva complejidad social que hace crecientemente obsoleto el modelo tradicional de bienestar es la que demanda unos nuevos servicios sociales universales dedicados a la protección y promoción de la interacción, basados en el conocimiento y la tecnología de evaluación e intervención e integrados vertical y horizontalmente, parece evidente que habrá de ser, también, crecientemente compleja la red de agentes implicados y crecientemente complejas sus relaciones, de modo que la intervención social sea capaz de dar cuenta de la complejidad social, de hacerle frente. Dentro de esa red de agentes, por su importancia en los servicios sociales y el trabajo por la inclusión, procede fijarse especialmente en las entidades de iniciativa social.

Al respecto, si bien la Ley vasca de Servicios Sociales apuesta preferentemente por el concierto social y determinados cambios recientes en la normativa europea han impulsado una ola de regulación de esta figura en otras comunidades autónomas, en el País Vasco no se ha producido el necesario desarrollo 
normativo, a pesar de que en 2016 se aprobó la Ley del Tercer Sector Social de Euskadi.

Sea como fuere, según el planteamiento presente en estas leyes, se entiende que las entidades de iniciativa social resultan de interés tanto cuando prestan servicios (en lo que nos interesa ahora, sociales) de responsabilidad pública como en el resto de sus actividades y funciones, aportando, en todo caso, un valor añadido específico y diferencial, en virtud del cual se justifica que sean objeto de fomento (en sus diversas actividades propias) y de discriminación positiva (en forma de cláusulas sociales, reserva de contratos u otras que les favorezcan) como gestoras de servicios públicos. Ese valor se verificaría, fundamentalmente, en la sinergia entre la prestación de los servicios en los términos establecidos y otras dinámicas (explícitas o implícitas en la normativa) como las de la acción voluntaria, la participación de las personas usuarias (y otras) en calidad de asociadas, el enraizamiento comunitario de la organización, su carácter inclusivo, el plus de compromiso de las trabajadoras, la conexión en red de la organización, la incorporación como trabajadoras (remunerados o voluntarias) de personas en situación de vulnerabilidad o exclusión, el valor intangible de la renuncia al beneficio económico, la independencia respecto del aparato público, el comercio justo, la gestión y financiación ética, el compromiso soportado con recursos propios, la utilidad pública, el interés social, la reputación en la comunidad u otros intangibles presentes en la cultura o ideología de la organización.

Por ejemplo, Ane Ferran (2016), en su tesis doctoral sobre Loiolaetxea como expresión de "la iniciativa social en la atención a las personas en riesgo o situación de exclusión en el marco de la política social guipuzcoana", sintetiza, finalmente, en cuatro aspectos la "aportación de valor" de esta obra de la Compañía de Jesús (ibídem: 410-413):

- La existencia de una comunidad de vida (independientemente de su cariz o motivación religiosa), el hecho de que en la casa conviva un grupo de personas de forma permanente y cotidiana [...]. Se trata de una presencia complementaria a la de los profesionales, más horizontal [...], lo que potencia terriblemente la integración comunitaria [...].

- Presentar la posibilidad de que las y los residentes reflexionen, compartan, cuestionen aspectos relacionados con la dimensión espiritual [...], una experiencia muy importante de diálogo interreligioso: la presencia de personas que profesan distintos credos [...].

- El abordaje del fracaso, de la recaída en el proceso personal [...], cuanta más flexibilidad, mayor posibilidad de adaptación.

- Capacidad para articular una red de apoyo comunitario [...], trabajar por tejer relaciones comunitarias. Entendemos que Loiolaetxea, al convertirse en un nodo más de la red, ayuda a tejer relaciones ciudadanas inclusivas.
Sin embargo, en recientes estudios de investigación (Rodríguez Cabrero, 2015) y procesos de reflexión estratégica (PONGAS, 2017) sobre el tercer sector de acción social en nuestro entorno, emerge la imagen de unas organizaciones excesivamente encajadas en procesos estandarizados de prestación de servicios sectoriales de responsabilidad y financiación pública, y un notable abandono de funciones de apoyo mutuo, innovación social, incidencia política y transformación social. Se echa de menos, especialmente el trabajo en red en el plano operativo (sobre todo, en el ámbito comunitario) y fuera del colectivo original de referencia. Así, por ejemplo, se ha detectado que "las actividades de desarrollo local o comunitario en el tercer sector de acción social se han reducido casi a la mitad entre 2008 y 2013" (Rodríguez Cabrero, 2015: 31). A partir de esta situación, el tercer sector de acción (con sus entidades) se plantea intentar alcanzar una situación en la que (PONGAS, 2017: 11):

1. Ofrece nuevas respuestas de calidad a las necesidades de las personas desde una gestión inteligente del factor humano, del conocimiento y de las nuevas tecnologías.

2. Es más transparente, más permeable a la comunidad, más participativo en su gobernanza, más amplio y equitativo en su base social.

3. Consolida un estatus de interlocutor ante todos los niveles de gobierno y participa en el diseño, ejecución y seguimiento de normas, políticas y decisiones que afectan al bienestar de la ciudadanía.

4. Multiplica su impacto en la opinión pública apoyándose en discursos compartidos, evidencias rigurosas y prácticas exitosas.

5. Cuenta(n) con capacidad operativa y sostenible para cumplir su misión y prestar una atención de calidad.

6. Alcanza mejores resultados a través de la colaboración interna entre entidades diversas y nuevas formas de cooperación con otros actores.

En lo que nos afecta en este artículo, se trataría, por tanto, de recuperar capacidad de estar en los dos lados de la ecuación, del lado de la intervención profesional del sistema público de servicios sociales y del lado de los activos comunitarios que pueden ser vistos como resultados esperados y apoyos complementarios por parte de los servicios sociales públicos o profesionales, de modo que la incorporación de entidades de la iniciativa social como prestadoras de servicios profesionales no acarree el sacrificio de sus potencialidades en clave de red preventiva, protectora, proactiva, comunitaria, voluntaria y solidaria.

Un marco posible para esta agenda de recuperación o reinvención de la iniciativa social y de la colaboración de diversos agentes en diferentes redes de conocimiento y acción puede ser el de la innovación social. Las consideradas como innovación suelen ser iniciativas de corte participativo, 
usualmente vinculadas a innovaciones tecnológicas y comunidades (al menos en parte) virtuales, impulsadas desde el trabajo en red y la hibridación entre diversas tradiciones, saberes y realidades organizacionales y sectoriales, planteadas a menudo como proyectos piloto o empresas emergentes que podrían luego llevarse a una escala mayor. Los planteamientos de la innovación social enfatizan la escucha a las personas usuarias o destinatarias $y$, en general, a todo agente (hablándose de innovación abierta, coproducción y cocreación); promueven intencional, activa, colaborativa y reticularmente la creatividad; juegan con la visualización de los sistemas y las soluciones; y trabajan con procesos de prototipado y experimentación rápida (Rodríguez Cabrero, 2015: 162-163). En su revisión de prácticas europeas de innovaciones sociales para la cohesión social, Adalbert Evers et al. (2014: 23) afirman que "aquellas que quieran dar a las innovaciones sociales un papel más importante tendrán que permitir grados de descentralización, diversidad, diferencia y además posibilidades de mezclas o fusiones no convencionales entre lo que normalmente está separado".

Las alertas críticas, en todo caso, no están de más, ya que, como señalan García y Rendueles (2017: 255):

Los cuestionamientos de las instituciones jerárquicas y la burocratización de la intervención social están dando lugar a la extensión de multitud de prácticas de innovación social basadas en las nuevas tecnologías y en las prácticas críticas de movimientos sociales para generar respuestas que ni la rigidez estatal ni la obsesión por la rentabilidad del mercado son capaces de abordar. Desde huertos urbanos a formas de economía colaborativa, pasando por aplicaciones informáticas de apoyo social y por prototipos arquitectónicos para mejorar un espacio comunitario, las acciones de innovación social están siendo cada vez más impulsadas por las instituciones públicas y el tercer sector. Sin embargo, en muchas ocasiones se confía a la innovación social la solución de problemas sociales sin pasar por la redistribución de renta y poder [...], aplicando recetas propias de las clases medias y las élites culturales a unos pobres que nuevamente mostrarán que no están a la altura de los tiempos.

La no linealidad y flexibilidad que, según se ha dicho, resultan procedentes en la intervención social y la atención integrada en favor de la inclusión social y sus objetivos de activación y participación parecen encajar bien con la utilización de dispositivos, aplicaciones, programas o plataformas que, mediante el procesamiento de diferentes tipos de datos provenientes de distintas fuentes y agentes, permitan activar de forma personalizada diversas capas de recursos, productos, activos o servicios, incrementando las oportunidades y la conectividad de las personas.

El reto es considerable, pues se trata de salir del círculo vicioso entre agravamiento de la situación de las personas, fragmentación de la atención, burocratización de las organizaciones e insatisfacción del personal; e impulsar el círculo virtuoso entre comunidad de conocimiento, integración de la atención, empoderamiento de las personas y sostenibilidad social. Ello requiere tanto de una más orientada investigación básica y aplicada, desde diversas áreas de conocimiento, que permita, como ya se ha dicho, mejorar el instrumental de evaluación de los fenómenos y cambios de los que nos ocupamos en los servicios sociales, como de experiencias piloto (prototipos) que vayan construyendo formatos e itinerarios de atención, y calibrando su utilidad, viabilidad, legitimidad, transferibilidad, escalabilidad y sostenibilidad.

El movimiento de la innovación social, pese a sus ambigüedades y contradicciones, puede ser adoptado como marco y método para el diseño, pilotaje y construcción de nuevas formas de sinergia (en la decisión, diseño, realización y evaluación en los servicios sociales) y escalabilidad entre: autocuidado, autodeterminación, y relaciones familiares y comunitarias; autogestión alternativa, iniciativa social, economía solidaria y movimientos sociales; emprendimiento empresarial, generación de empleo e inversión de capital; y garantía de derechos y liderazgo político. En ese contexto, se pide al tercer sector: capacidad de abrir agendas para la relación entre las iniciativas innovadoras ('brotes') y las más resilientes ('juncos'), que han evitado convertirse en 'zombis'; recuperación de valores y funciones que han quedado arrinconados por una dedicación excesiva en muchas organizaciones a la prestación de servicios estandarizados con dinero público; y, fundamentalmente, una repolitización en función de la cual su capacidad de producción y gestión de bienes comunes se convierta en el mejor aliado contra los riesgos de privatización o burocratización del sector público, mercantilización y fragmentación de la sociedad e incremento, en definitiva, de la exclusión social. 
AGUILAR HENDRICKSON, M. (2014): Apuntes para un replanteamiento de los servicios sociales en España, serie Documentos de Trabajo del VII Informe sobre Exclusión y Desarrollo Social en España, $n^{\circ}$ 5.12, Madrid, Fundación Foessa.

AGUILAR HENDRICKSON, M. et al. (2012): "Los servicios sociales ante la exclusión", Zerbitzuan, $\mathrm{n} \times 51$, págs. 9-26 [shttps://doi.org/10.5569/1134$7147 / 51.01\rangle]$

AGUIRRE, B. (2013): “El acompañamiento social personalizado como fórmula innovadora de respuesta a personas con trastorno mental y en exclusión social", Zerbitzuan, nํㅜ 54 , págs. 127-137 ['https://doi.org/10.5569/11347147.54.08>]

ARARTEKO (2016): La situación de los servicios sociales municipales en la Comunidad Autónoma de Euskadi, Vitoria-Gasteiz, Ararteko.

ARRIETA, F. (2015): "Factores determinantes de la complejidad del Sistema Vasco de Servicios Sociales y sus efectos en la provisión territorial de servicios" [tesis doctoral], Universidad de Deusto, Facultad de Ciencias Sociales y Humanas.

BLANCO, J. et al. (2015a): Manual Inclúe, Donostia, Emaús.

- (2015b): Modelo Inclúe, Donostia, Emaús.

CARDONA, J. et al. (2017): “La comprensión de la situación problema en la práctica del trabajo social de casos. Resultados de una investigación", Cuadernos de Trabajo Social, vol. 30, $\mathrm{n}-1$, págs. 149-162.

CARRETERO, S. (2015): Mapping of Effective Technologybased Services for Independent Living for Older People at Home, Sevilla, Institute for Prospective Technological Studies.
CASADO, D. (2017): “Discapacidad y dependencia: apoyos a familiares cuidadores", Políticas Sociales en Europa, no38-39, págs. 7-29.

COLOMBO, F. (2016): "Housing First as a strategy to address social exclusion? Findings from a comparative case study research in Europe", en ESPANET ITALIA, IX Conferenza anuale. Modelli di welfare e modelli di capitalismo. Le sfide per lo sviluppo socio-economico in Italia e in Europa, Macerata.

DUQUE, J. M. (2014): “Políticas de servicios sociales para la atención a personas en situación de exclusión residencial grave. Elementos para un diagnóstico y propuestas estratégicas", Zerbitzuan, n- 55 , págs. 35-46 [<https://doi. org/10.5569/1134-7147.55.03>].

ESPAÑA (2006): “Ley 39/2006, de 14 de diciembre, de Promoción de la Autonomía Personal y Atención a las Personas en Situación de Dependencia”, Boletín Oficial del Estado, no 299, 15-12-06, págs. 44.142-44.156 [khttps://www.boe.es/ diario_boe/txt.php?id=BOE-A-2006-21990〉].

EVERS, A. et al. (2014): Social Innovation for Social Cohesion. Transnational Patterns and Approaches from 20 European Cities, Giesen, WILCO.

FANTOVA, F. (2016): "La intervención social en la garantía de ingresos y en los servicios sociales. Análisis y propuestas desde la experiencia del País Vasco", Servicios Sociales y Política Social, vol. XXXIII, nํㅜ110, págs. 33-45.

- (2014): Diseño de políticas sociales. Fundamentos, estructura y propuestas, Madrid, CCS.

- (2008): Sistemas públicos de servicios sociales. Nuevos derechos, nuevas respuestas, Bilbao, Universidad de Deusto. 
- (2007): "Repensando la intervención social", Documentación Social, no - 147, págs. 183-198.

FANTOVA, F. et al. (2005): Situación y perspectivas del sistema público de servicios sociales en la Comunidad Autónoma del País Vasco, VitoriaGasteiz, Eusko Jaurlaritza-Gobierno Vasco.

FERRAN, A. (2016): “Loiolaetxea: respuesta a la exclusión desde la solidaridad" [tesis doctoral], Departamento de Trabajo Social y Sociología, Universidad de Deusto.

GARCÍA GARCÍA, S.; y RENDUELES, C. (2017): "Hacia un nuevo trabajo social crítico: el gobierno de lo social en la era neoliberal", Cuadernos de Trabajo Social, vol. 30, no 2, págs. 243-260.

GARCÍA-LONGORIA, M. P.; y ESTEBAN PALOMARES, R. M. (2016): Análisis y diagnóstico en trabajo social, Valencia, Tirant lo Blanch.

IRIBAR, J. (2017): “Servicios de primaria y secundaria que comparten equipamiento. Experiencias en Gipuzkoa: posibilidades y dificultades", Zerbitzuan, no 63, págs. 49-56 [<https://doi. org/10.5569/1134-7147.63.02>].

JARAÍZ, G.; y GONZÁLEZ PORTILLO A. (2014): "Transformaciones y retos relacionales en el ámbito de los servicios sociales comunitarios", Documentación Social, no - 175, págs. 133-156.

LAPARRA, M. et al. (2007): "Una propuesta de consenso sobre el concepto de exclusión. Implicaciones metodológicas”, Revista Española del Tercer Sector, $\mathrm{n} \div 5$, págs. $15-57$.

LÓPEZ-ARÓSTEGUI, R. (2016): Ley de Servicios Sociales y Decreto de Cartera de Prestaciones y Servicios de la Comunidad Autónoma del País Vasco: aproximación a la intervención socioeducativa en el nuevo escenario de los servicios sociales, Bilbao, Colegio de Educadoras y Educadores Sociales del País Vasco.

MCNEIL, C.; y HUNTER, J. (2015): Towards a 'Troubled Lives' Programme for People Facing Multiple and Complex Needs, Londres, IPPR.

OCDE (2017): Behavioural Insights and Public Policy: Lessons from around the World, París, Organización para la Cooperación y el Desarrollo Económico.

- (2015): Integrating Social Services for Vulnerable Groups Bridging Sectors for Better Service Delivery, París, Organización para la Cooperación y el Desarrollo Económico.

ONU (2001): Clasificación Internacional del Funcionamiento, la Discapacidad y la Salud. Edición abreviada, Madrid, Imserso.

ORBEGOZO, A. (2016): “Regulación del diagnóstico social en el País Vasco: intenciones, resultados y vericuetos", Zerbitzuan, nํ61, págs. 21-32 ['https://doi.org/10.5569/1134-7147.61.02〉].

ORMAETXEA, I. (2017): "Perfiles, apoyos criterios" [presentación], en IV Jornadas Gizartegune 'Transformando el modelo de intervención para la inclusión social', Bilbao, Bizkaiko Foru Aldundia-Diputación Foral de Bizkaia [<http:// www.bizkaia.eus/home2/Temas/DetalleTema. asp?Tem_Codigo $=10444$ \&idioma $=$ CA\&dpto_ biz=9\&_odpath_biz=9|9532|10445|10444'].
- (2011): Jornadas de Presentación del Instrumento Técnico Común de Valoración de la Exclusión Social, Vitoria-Gasteiz, Eusko Jaurlaritza-Gobierno Vasco.

ORTÚN-RUBIO, V.; y LÓPEZ-CASASNOVAS, G. (2002): Financiación capitativa, articulación entre niveles asistenciales y descentralización de las organizaciones sanitarias, Bilbao, Fundación BBVA.

PAÍS VASCO (2017): “Decreto 152/2017, de 9 de mayo, por el que se aprueba la actualización del Instrumento para la Valoración de la Gravedad de las Situaciones de Riesgo y Desamparo en los Servicios Sociales Municipales y Territoriales de Atención y Protección a la Infancia y Adolescencia en la Comunidad Autónoma del País Vasco (Balora)", Boletín Oficial del País Vasco, no 125, 3-7-17 [<https:// www.euskadi.eus/y22-bopv/es/bopv2/ datos/2017/07/1703354a.shtmls].

- (2016) "Ley 6/2016, de 12 de mayo, del Tercer Sector Social de Euskadi”, Boletín Oficial del País Vasco, no 94, 12-5-16 [<https:// www.euskadi.eus/y22-bopv/es/bopv2/ datos/2016/05/1602096a.shtmlı].

- (2015): “Decreto 185/2015, de 6 de octubre, de Cartera de Prestaciones y Servicios del Sistema Vasco de Servicios Sociales", Boletín Oficial del País Vasco, ํㅜ 206, 29-10-15, págs. 1-87 [rhttps:// www.euskadi.eus/y22-bopv/es/bopv2/ datos/2015/10/1504561a.shtml>].

- (2015): “Ley 3/2015, de 18 de junio, de Vivienda”, Boletín Oficial del País Vasco, n-9 94, 19-5-16 [rhttps:// www.euskadi.eus/y22-bopv/es/bopv2/ datos/2016/05/1602096a.shtml〉].

- (2013): “Decreto 385/2013, de 16 de julio, por el que se aprueba el Instrumento de Valoración de la Exclusión Social”, Boletín Oficial del País Vasco, no $149,7-8-13$ [<https://www.euskadi.eus/ y22-bopv/es/bopv2/datos/2013/08/1303530a. shtml>].

- (2013): “Decreto 353/2013, de 28 de mayo, de Ficha Social del Sistema Vasco de Servicios Sociales y del Instrumento de Diagnóstico Social del Sistema Vasco de Servicios Sociales", Boletín Oficial del País Vasco, no 121, 16-6-13 [<https:// www.euskadi.eus/y22-bopv/es/bopv2/ datos/2013/06/1302907a.shtmls].

- (2011): “Ley 4/2011, de 24 de noviembre, de modificación de la Ley para la Garantía de Ingresos y para la Inclusión Social”, Boletín Oficial del País Vasco, nํㅜ 233, 12-12-11 ['https:// www.euskadi.eus/r47-bopvapps/es/bopv2/ datos/2011/12/1105924a.shtml>].

- (2008): “Ley 18/2008, de 23 de diciembre, para la Garantía de Ingresos y para la Inclusión Social”, Boletín Oficial del País Vasco, n을 250, 31-12-08 [khttps://www.euskadi.eus/r47-bopvvaci/es/ bopv2/datos/2008/12/0807235a.shtml)].

- (2008): “Ley 12/2008, de 5 de diciembre, de Servicios Sociales", Boletín Oficial del País Vasco, no 246, 24-12-08, págs. 31.840-31.924 [khttps:// www.euskadi.eus/r47-bopvapps/es/bopv2/ datos/2008/12/0807143a.shtml〉].

- (1996): “Ley 5/1996, de 18 de octubre, de Servicios Sociales”, Boletín Oficial del País Vasco, 꿀 218, 
12-11-96 [<https://www.euskadi.eus/y22-bopv/ es/bopv2/datos/1996/11/9605350a.shtmls].

PONGAS (2017): Nuestro compromiso con la sociedad. III Plan Estratégico del Tercer Sector de Acción Social, Madrid, Plataforma de Organizaciones No Gubernamentales de Acción Social.

RODRÍGUEZ CABRERO, G. (dir.) (2015): Análisis prospectivo sobre los retos actuales y futuros del Tercer Sector de Acción Social, Madrid, Plataforma de Organizaciones No Gubernamentales de Acción Social.

RUIZ, P.; y BETETA, P. (2016): “Reflexión sobre la baja exigencia: una aproximación al trabajo con personas en exclusión residencial grave", Zerbitzuan, no 61, págs. 33-52 [<https://doi. org/10.5569/1134-7147.61.03〉].
SCHALOCK, R. et al. (2008): "Enhancing personal outcomes: Organizational strategies, guidelines and examples", Journal of Policy and Practice in Intellectual Disabilities, vol. $5, \mathrm{n}-4$, págs. 276-285.

SIIS CENTRO DE DOCUMENTACIÓN Y ESTUDIOS (2015): "Reordenación de la red de recursos y programas para la inclusión social de Gipuzkoa”, Zerbitzuan, nํ⒌ 59, págs. 5-38 [<https://doi.org/10.5569/1134-7147.59.01〉].

ZALAKAIN, J. (2013). "Tendencias y prácticas innovadoras en inclusión social. Perspectiva internacional”, Lan Harremanak, no 29, págs. 171-212. 